\title{
Evolution of Precipitation Structure During the November DYNAMO MJO Event: Cloud-Resolving Model Inter-comparison and Cross-Validation using Radar Observations
}

\author{
By
}

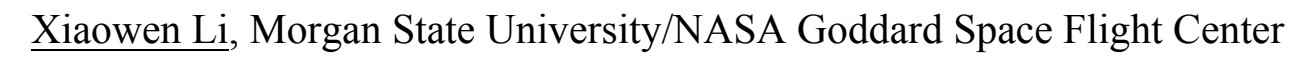

10 Matthew A. Janiga, University of Miami*

12 Wei-Kuo Tao, NASA Goddard Space Flight Center

13 Angela Rowe, University of Washington

$14 \quad$ Weixin $\mathrm{Xu}$, Colorado State University

15 Chuntao Liu, Texas A\&M, University at Corpus Christi

16 Toshihisa Matsui, ESSIC, University of Maryland, College Park/NASA Goddard Space Flight

17 Center

18 Chidong Zhang, NOAA Pacific Marine Environmental Laboratory

Key Points:

- Multi-radar observations allow stringent multi-model comparisons and validation for precipitation structures during an MJO event

- Cloud-resolving models constrained by site-specific observed large-scale forcing can reproduce variations of radar echo-top heights

- The multi-radar, multi-model framework also benefits quantitative sensitivity studies to highlight common model strength and weakness

40

A manuscript submitted to the Journal of Geophysical Research

September 2017, revised December 2017

Accepted February, 2018 
Abstract

47 Evolution of precipitation structures are simulated and compared with radar observations for the

48 November Madden-Julian Oscillation (MJO) event during the DYNAmics of the MJO 49 (DYNAMO) field campaign. Three ground-based, ship-borne, and space-borne precipitation 50 radars and three Cloud-Resolving Models (CRMs) driven by observed large-scale forcing are 51 used to study precipitation structures at different locations over the central equatorial Indian 52 Ocean. Convective strength is represented by 0 -dBZ echo-top heights, and convective 53 organization by contiguous $17-\mathrm{dBZ}$ areas. The multi-radar and multi-model framework allows 54 for more stringent model validations. The emphasis is on testing models' ability to simulate 55 subtle differences observed at different radar sites when the MJO event passed through. The 56 results show that CRMs forced by site-specific large-scale forcing can reproduce not only

57 common features in cloud populations, but also subtle variations observed by different radars.

58 The comparisons also revealed common deficiencies in CRM simulations where they 59 underestimate radar echo-top heights for the strongest convection within large, organized 60 precipitation features.

61

62 Cross-validations with multiple radars and models also enable quantitative comparisons in CRM 63 sensitivity studies using different large-scale forcing, microphysical schemes and parameters, 64 resolutions, and domain sizes. In terms of radar echo-top height temporal variations, many model 65 sensitivity tests have better correlations than radar/model comparisons, indicating robustness in 66 model performance on this aspect. It is further shown that well-validated model simulations 67 could be used to constrain uncertainties in observed echo-top heights when the low-resolution 68 surveillance scanning strategy is used. 
72 Full understanding of cloud and precipitation processes, and their impact on the surrounding 73 environment, requires detailed information of precipitation structure and morphology, e.g., 74 cloud-top heights and their spatial and temporal variations, the horizontal extent and the degree 75 of organization of precipitation systems. For example, radar echo-top heights and their spatial 76 and temporal distributions indicate the location of moistening and heating [e.g., Masunaga et al., 77 2006; Lau and Wu, 2010; Ahmed et al., 2016]; the spatial extent and organization of precipitation 78 features are linked to different vertical distributions of latent heating, with small, scattered 79 precipitation producing bottom-heavy heating, and large, organized precipitation systems 80 resulting in top-heavy heating in a widespread stratiform region. Such detailed three-dimensional 81 (3-D) information of cloud and precipitation structure comes from only two sources: radar 82 observations and cloud-resolving model (CRM) simulations.

84 The DYNAmics of the Madden-Julian Oscillation (DYNAMO) field experiment (October 2011 85 - March 2012) ${ }^{1}$ was carried out in the central tropical Indian Ocean to study MJO convective 86 initiation processes and to improve MJO predictions [Yoneyama et al., 2013]. Two sounding 87 arrays together with multiple ground-based radars (Fig. 1) provide a rich dataset for studying 3-D 88 precipitation structures and their associated environment during the MJO onset and mature stage. 89 The current study focuses on the Northern Sounding Array (NSA) for the DYNAMO November 90 MJO event because signals in temporal variations of this MJO event within the NSA are much 91 stronger than in the Southern Sounding Array [Johnson and Ciesielski, 2013; Johnson et al., 92 2015]. The NSA is defined by four sounding sites at Malé, Colombo, Addu Atoll, and the R/V 93 Roger Revelle [Ciesielski et al., 2014]. Multi-frequency, dual-polarization, ground-based radars 94 were deployed both at the Addu site and onboard the R/V Roger Revelle. In addition, the space95 borne Precipitation Radar (PR) onboard the Tropical Rainfall Measurement Mission (TRMM) 96 satellite also provided 3-D echo structure over a larger domain than the ground-based radars, but 97 with lower sensitivity and less frequent sampling. These radar observations have been compared 98 in previous studies. For example, Xu et al. [2015] compared radar observed echo-top heights,

\footnotetext{
${ }^{1}$ DYNAMO is a joint project with CINDY2011 (Cooperative Indian Ocean Experiment on Intraseasonal Variability in the Year 2011), AMIE (ARM MJO Investigation Experiment), and LASP (Littoral Air-Sea Process).
} 
99 stratiform rain fractions, and precipitation feature sizes at Addu Atoll, R/V Roger Revelle, and $100 \mathrm{R} / \mathrm{V}$ Mirai. They concluded that despite some subtle differences in the rate of convective 101 deepening, convection at Addu Atoll $\left(0.7^{\circ} \mathrm{S}, 73.1^{\circ} \mathrm{E}\right)$ and R/V Roger Revelle $\left(0^{\circ}, 80.5^{\circ} \mathrm{E}\right)$, which 102 were about $825 \mathrm{~km}$ apart along the equator, showed similar temporal variability throughout the 103 MJO lifecycle, especially when compared to the $\mathrm{R} / \mathrm{V}$ Mirai $\left(8^{\circ} \mathrm{S}, 80.5^{\circ} \mathrm{E}\right)$ radar, located to the

104 south of the equator, which showed nearly opposite precipitation patterns compared to the 105 Revelle radar. Xu and Rutledge [2014], Powell and Houze Jr. [2015], and Xu and Rutledge 106 [2015] compared ground-based radars and TRMM PR long-term observations and noted that the 107 variability observed by the S-PolKa radar at Addu Atoll and the Revelle C-band radar were 108 consistent with TRMM-PR observations. These radar observations therefore provide a useful, 109 consistent database to validate CRM simulations, which, in turn, allows for an additional 110 investigation into the commonalities and subtle differences between the different regions during 111 the same MJO event.

112

113 CRMs are important tools for studying precipitation structure because of their ability to 114 explicitly resolve deep convective dynamics, as opposed to parameterizing them in coarse 115 resolution models. Generally, there are two different approaches for the limited area cloud116 resolving simulations (usually with horizontal resolution of less than $4 \mathrm{~km}$ ). One is to use CRMs 117 in the forecast mode, where time-variant large-scale influences come from lateral boundaries. 118 The other is to use the observed large-scale forcing and apply it uniformly in the model domain 119 with cyclic lateral boundary conditions. Both approaches have been used in previous DYNAMO 120 case studies. With the first approach, Hagos et al. [2014a, b] used the Weather Research and 121 Forecasting (WRF) model to simulate DYNAMO MJO events and tested different microphysical 122 packages. Although WRF captured many general features of the MJO evolution, it overestimated 123 radar reflectivity for deep convective cells compared with the S-PolKa observations. Wang et al. 124 [2015a] applied a regional setup of WRF and were also able to simulate the MJO characteristics 125 as well as its moist static energy budget with a coarser horizontal spacing of $9 \mathrm{~km}$. Other studies 126 have used the second approach with cyclic boundary conditions and large-scale forcing. For 127 example, Janiga and Zhang [2016] used the System for Atmospheric Modeling (SAM) 128 [Khairoutdinov and Randall, 2003] to analyze the moisture budget during DYNAMO; Wang et 129 al. [2015b] studied the cloud-radiation interactions using WRF. They identified significant 
130 spread in radiative fluxes and stratiform cloud coverage when different microphysical schemes 131 are used. Wang et al. [2016] further demonstrated important roles of horizontal advection of 132 moisture and radiative feedback in driving the MJO in their WRF simulations with 133 parameterized large-scale dynamics. These studies used the large-scale forcing approach because 134 it guarantees accurate simulations of domain-mean moisture budget and surface precipitation. 135 This provides a better constraint when the evolution of precipitation structures is validated 136 against radar observations. Simulations using the first approach do not guarantee agreements in 137 surface rainfall and its temporal variations. The current study uses the large-scale forcing 138 approach.

140 The combination of observations from the multiple DYNAMO radars and different CRM 141 simulations provides a unique opportunity to study the evolution of 3-D cloud and precipitation 142 structures during convective initiation of the MJO, and their interactions with large-scale 143 environment. The main challenge exists in interpreting discrepancies in simulations resulting 144 from using different models, configurations, forcing, and observational validations. This is 145 crucial for both CRM sensitivity studies and radar data interpretation aiming at understanding 146 MJO mechanisms. The current study attempts to meet this challenge with three goals.

148 The first goal is to find out if, and to what extent, a CRM is able to simulate subtle differences in 149 precipitation evolution of the same MJO event observed by radars at different locations with 150 different sampling sizes. Observations by the S-PolKa radar on Addu Atoll [Rowe and Houze, 151 2014], the C-band radar onboard R/V Roger Revelle [Xu and Rutledge, 2015], and the TRMM 152 PR covering the whole NSA area, including both Addu and Revelle sites, are analyzed to show 153 similarities and differences in their convective properties and evolution. Their similarities are 154 used to validate the Goddard Cumulus Ensemble (GCE) model [e.g., Tao et al., 2014], which is 155 then used to understand the nature of the subtle differences in different radar observations.

157 The second goal of the current study is to quantify differences in simulated cloud structure and 158 their variability during an MJO event resulting from using different CRMs and different model 159 configurations. In this study, three CRMs, namely, GCE, WRF and SAM, are used with the 160 identical large-scale forcing for the DYNAMO November MJO event. This approach almost 
161 always results in desired matches in domain mean precipitation and total heating between the 162 model and the observations. Once the mean state is realistically simulated, comparisons between 163 the models and radar observations, as well as among models themselves, can be carried out with 164 high confidence [e.g., Fridlind et al., 2012; Wang et al., 2015b].

166 The third goal of our study is to cross-compare simulations by different CRMs to observations 167 from different DYNAMO radars. Previous model validation studies generally treat observations 168 as the truth with pre-determined instrument errors. Multiple radar observations during the 169 DYNAMO field campaign, together with radar-specific large-scale forcing for driving CRMs, 170 may allow us to differentiate natural variabilities and observation uncertainties in precipitation 171 structures. If the variability among radar observations is smaller than that among models, 172 quantitative error margins may be derived for different model simulations. Otherwise, it could 173 mean that the models perform within the error margin of radar observations and may be used, in 174 some occasions, to help interpret differences in radar data. To achieve the third goal, several 175 methods are used to reduce inter-model discrepancies. For example, all model simulations are 176 carefully matched and coordinated. A radar simulator is used to avoid retrieval errors, and to 177 match each radar's sampling strategy. Qualitative variables that are less sensitive to intermodel/inter-instrument differences (e.g., the 0-dBZ echo-top height) are used instead of more quantitative statistics such as radar Contour Frequency with Altitude Diagrams [Yuter and Houze,

182 The remainder of this study is divided into six sections: Section 2 describes DYNAMO sounding 183 and radar data, as well as the three CRMs. Section 3 discusses GCE simulations using three 184 different large-scale forcing datasets and compares them with corresponding radar observations 185 in order to understand the natural variability of precipitation structures due to different radar 186 sampling strategies. Section 4 compares simulations by three different CRMs using the same 187 large-scale forcing. Section 5 presents sensitivity tests of the GCE model to its domain size and 188 vertical resolution, as well as selected parameters that could affect the simulated echo-top heights 189 of deep convection. Section 6 explores cross-validations using multi-radar and multi-model 190 results and attempts to quantify both model and radar variability. Discussions and a summary are 191 given in Section 7. 


\section{Radar and Model Descriptions}

\subsection{Radar Observations}

During the DYNAMO campaign, two scanning radars were deployed on Addu Atoll: the dual-

198 frequency S- (10 cm wavelength) and Ka- $(0.86 \mathrm{~cm}$ wavelength) S-PolKa radar operated by the

199 National Center of Atmospheric Research, and the C-band (5 cm wavelength) SMART-R radar 200 operated by Texas A\&M University. Both radars have excellent temporal coverage, but the S201 band data from S-PolKa is used in this study due to its better spatial coverage compared with 202 SMART-R, which experienced partial beam blockage, and also due to its additional Range 203 Height Indicator (RHI) scans with improved vertical resolution. Gridded S-PolKa radar 204 reflectivity, its retrieved surface rainfall rate, and convective/stratiform separation were provided 205 by the University of Washington radar group. The S-PolKa radar has a scanning radius of 150 $206 \mathrm{~km}$ and temporal resolution of 15 minutes. The surveillance (SUR) $360^{\circ}$ azimuth scanning data, 207 with only 8 elevation angles up to $11^{\circ}$, were interpolated onto $0.5 \mathrm{~km}$ Cartesian grids both 208 horizontally and vertically. To compensate for the coarse vertical resolution of the SUR data, S209 PolKa also performs the RHI scans at $1^{\circ}$ azimuthal resolution up to $45^{\circ}$ elevation, but for a 210 limited scanning range toward the open ocean [Rowe and Houze, 2014]. In this study, SUR data 211 were used for deriving the site-specific large-scale forcing, and will be used mainly for model 212 validations. The RHI data were used to corroborate and validate SUR observations.

214 The R/V Roger Revelle was deployed due east of Addu Atoll at the equator (cf. Fig. 1). It carried 215 out four separate cruises to the site during the campaign. As a result, there are gaps in radar 216 observations, although most of the missing data periods are during the suppressed MJO phases. 217 The NASA TOGA C-band (5-cm wavelength) radar data are processed and provided by the 218 Colorado State University radar group. It has the same scanning radius of $150 \mathrm{~km}$ as the S-PolKa, 219 but with a wider beam width $\left(1.5^{\circ}\right.$ vs. $0.91^{\circ}$ for S-PolKa). The data are gridded with 2-km 220 horizontal resolution, 0.5-km vertical resolution, and 10-minute temporal resolution. Details of 221 the C-band radar can be found in [Xu and Rutledge, 2014]. For the purpose of comparing radar 222 observations with CRMs, only data points within the range between $20 \mathrm{~km}$ and 100-km range are 
used in this study due to sampling errors. The rationale of using this range will be presented in

224 section 6.

Both ground-based and space-borne radars provide highly valuable information on precipitation structures, with different characteristics in spatial and temporal coverage. Ground-based radars operate continuously and provide excellent temporal resolution. However, both the S-PolKa and C-band radar are at fixed locations and their spatial coverage are limited by their detection ranges. The space-borne radar, e.g., the Ku-band (2-cm wavelength) TRMM PR scanning radar, has large spatial coverage with a swath of about $250 \mathrm{~km}$. However, its temporal coverage is relatively poor. Sampling frequency for the area covered by the NSA (Fig. 1) is about twice a day. TRMM PR's footprint is about $5 \mathrm{~km}$, which is much coarser than the resolutions of the surface radars. However, it has a high vertical resolution at $250 \mathrm{~m}$. Its minimum detectable signal is about $17 \mathrm{dBZ}$, much less sensitive than the ground-based radars (better than $0 \mathrm{dBZ}$ ). The TRMM orbital data product 2A25 (version 7), post-processed to form the TRMM precipitation feature database [Liu et al., 2008], is used to compare radar echo-top heights and precipitation feature sizes. TRMM surface rainfall data are based on gridded TRMM 3B42 product due to its high temporal resolution $\left(0.25^{\circ} \times 0.25^{\circ}, 3\right.$-hourly) [Huffman et al., 2007].

\subsection{Large-Scale Forcing}

Three independent radar observations with different sampling sizes during the DYNAMO field campaign provide a unique opportunity for model validations and comparisons. These radar observations are well correlated [Xu et al., 2015] but still have differences due to their different locations and sampling methods. They are used in this study to test the CRMs' capability of reproducing both the similarities and differences in observations. In order to do this, three largescale forcing datasets derived by two research groups independently using different methods are used to drive CRMs. al., 2015]. It uses 4 sounding stations defining the NSA (Fig. 1) to derive water vapor and 
254 resolution of the NSA forcing is 4 times daily. The NSA forcing used in this study is version 2a, 255 which includes observations only without any global analysis data. The advantage of the NSA 256 forcing is that it has large spatial coverage (roughly $7^{\circ} \times 7^{\circ}$ ) and is representative of the mean

257 budget characteristics during the DYNAMO November MJO event. TRMM PR observations are 258 used to compare with simulations driven by the NSA forcing over this large domain.

260 Large-scale forcing for both the Addu site (S-PolKa radar) and Revelle site (C-band radar) were 261 derived by the Lawrence Livermore National Lab, using variational analysis [Xie et al., 2010; 262 Zhang et al., 2001; Zhang and Lin, 1997]. The variational analysis uses domain-average surface 263 and top-of-the-atmosphere radiation, surface fluxes and precipitation as constraints to adjust 264 atmospheric state variables from sounding profiles by the smallest possible amount to conserve 265 column-integrated mass, moisture, and static energy. ECWMF analysis data were used to derive 266 the large-scale forcing 8 times daily. Surface precipitation amount uses radar-retrieved surface 267 rainfall from the SUR scans. The matches between the large-scale forcing domain and the radar 268 sampling domain ensures an apple-to-apple comparison between model simulations and radar 269 observations.

\subsection{Model Descriptions}

272

Three different CRMs are used to simulate the November MJO event: the Goddard Cumulus Ensemble (GCE) model [e.g., Tao et al., 2009], the System for Atmospheric Modeling (SAM) [e.g., Khairoutdinov and Randall, 2003; Janiga and Zhang, 2016], and the Weather Research and Forecasting (WRF) model version 3.5 [Skamarock et al., 2008] modified for cloud-resolving simulations with prescribed or parameterized large-scale forcing [e.g., Wang and Sobel, 2011; Wang et al., 2013; Anber et al., 2014; Wang et al., 2015b]. These simulations, referred to as inter-comparison simulations, have been carefully designed and coordinated to minimize uncertainties in their experimental setup. For example, all three models are driven by the same large-scale forcing (NSA), which includes advection of moisture and temperature, as well as domain mean horizontal winds. All three models use the same domain size, grid spacing, and start at the same time. Other numerical parameters, such as damping layers near the top of the model domain, as well as the associated damping coefficients, are also specified to be identical. 
285 The inter-comparison simulations have $256 \times 256 \times 106$ grids, with horizontal grid spacing of $1 \mathrm{~km}$.

286 The nominal vertical grid spacing is $0.25 \mathrm{~km}$, with a higher resolution in the planetary boundary 287 layer, and a stretching, lower resolution from $18 \mathrm{~km}$ to about $30 \mathrm{~km}$. All three models use the 2288 moment Morrison microphysical scheme [Morrison et al., 2005], although with slightly different 289 versions inherited from every model's implementation. On the other hand, the CRMs differ in 290 many other aspects. Each CRM has its own dynamics, numerical methods, and subgrid turbulent 291 mixing parameterizations. Radiation schemes also differ (Table 1).

293 In addition to inter-comparison simulations, the GCE model is used for sensitivity studies on 294 different forcing data, different microphysical packages, as well as varying domain size and 295 vertical spacing. Table 1 summarizes some of the key parameters of CRM simulations. In order 296 to differentiate ground-based radar data from their corresponding large-scale forcing, we will use 297 the radar frequency (S-PolKa and C-band) when we refer to radar observations in our discussion, 298 and use the location (Addu and Revelle) to represent model simulations using the radar specific 299 large-scale forcing.

300

\section{3. Comparisons of GCE Simulations and Radar Observations}

303 Two different large-scale forcing data are derived separately for the Addu and Revelle site in 304 order to account for the differences in their rainfall observations and associated environment. 305 Because surface radar has limited coverage ( $\sim 150 \mathrm{~km}$ radius), and the organized precipitation 306 systems associated with an MJO can be larger than that, using large-scale forcing specific to a 307 single radar and constrained by its own retrieved surface rainfall can significantly reduce 308 uncertainties in radar/model comparisons. Furthermore, to ensure an apple-to-apple comparison, 309 a forward radar simulator [Matsui et al., 2009; Matsui et al., 2013] has been used to derive radar 310 reflectivity from model-simulated hydrometeors with the same microphysics assumptions. The 311 more realistic Mie scattering is used for both the $\mathrm{C}$ - and $\mathrm{Ku}$-band radar. S-band radar reflectivity 312 is calculated using Rayleigh approximation, which is a reasonable assumption at longer 313 wavelengths. GCE simulations using the large-scale forcing specific to each individual radar. 314 They have a domain size of $256 \mathrm{~km} \times 256 \mathrm{~km}$, with the horizontal spacing of $1 \mathrm{~km}$, and 315 stretching vertical grids with the nominal resolution of $0.5 \mathrm{~km}$. The microphysics used is the 
316 Goddard 3-ICE package, which is a single-moment scheme including cloud, rain and three ice317 phase species: ice, snow aggregates and graupel [Tao et al., 2009].

319 The CRM-simulated precipitation structures are compared with radar observations in both spatial 320 and time dimensions. In the vertical, the 0-dBZ echo-top height distributions and their temporal 321 variations are compared. In the horizontal dimension, the convective/stratiform separation and 322 the precipitation feature sizes are compared. The precipitation feature size will also be used as an 323 indication of convection organization. The lack of large precipitation features generally indicates 324 scattered, less organized convection, and vice versa. Correlations between horizontal feature 325 sizes and the maximum echo-top heights within the contiguous precipitation feature are also 326 compared. Additional comparisons of basic model fields, e.g., the apparent heat source and moist 327 sink, temperature profiles, are carried out against observations. They generally have very good 328 agreements, as should be for a balanced large-scale forcing (plots not shown).

\subsection{Surface Rainfall}

Figure $2 \mathrm{a}$ and $2 \mathrm{~b}$ show the S-PolKa radar and C-band radar retrieved mean surface rainfall with 334 November 13. For each independent forcing data, GCE model reproduces the mean surface rainfall trends very well. This is because the domain-mean heat and water vapor budget are constrained tightly by the prescribed large-scale forcing. The two different observations, however, agree with each other only qualitatively in that they all captured the enhanced surface rainfall during the mature stage of the MJO event (21-30 November), and the suppressed rainfall 340 November, indicating passages of two Kelvin wave events [e.g., Depasquale et al., 2014]. On 341 the other hand, observations differ in quantitative details. For example, the C-band radar 342 retrieved MJO rainfall peak lags S-PolKa retrieval and the NSA forcing derived rainfall peak by 343 about 20 hours. This lag is because the Revelle was stationed about $7^{\circ}$ to the east of Addu radar 344 site [Xu et al., 2015]. The rainfall rate is more episodic at the Addu site, dominated by passages 345 of individual events separated by low rainfall periods. For example, there are two consecutive 346 high rain rate events during the developing stage around November 18. Furthermore, the peak 
347 rainfall rate at Addu is twice as much compared with the C-band radar, indicating stronger 348 convective events both during the developing and mature stages of MJO. Given the differences 349 in surface rainfall observed at different locations, and ground-based radar's limited spatial 350 coverage, it would be optimal to use location specific large-scale forcing, as in this study, to 351 ensure accurate model and observation comparisons. For example, if one used the NSA forcing 352 and compared the surface rainfall with the S-PolKa radar retrieval, the correlation would have

353 been much lower. With the GCE model accurately reproducing mean surface rainfall variability,

354 the next question to address is: How well can the CRMs quantitatively reproduce the variability 355 of cloud structures during the MJO event, given the tight constraint of the surface rainfall? 356 Whether the GCE model can reproduce subtle differences at different radar sites will also be a 357 unique test for model performance.

\subsection{Vertical Structure}

Figure 3 compares vertical distributions of the 0 -dBZ radar echo-top heights between the S362 PolKa radar observations (3a) and GCE simulation using Addu forcing (3b); C-band radar 363 observations (3c) and GCE simulation using Revelle forcing (3d). The 0-dBZ echo-top height is 364 calculated by searching from the ground up for contiguous reflectivity values above $0 \mathrm{dBZ}$. All 365 model data have been interpolated on the observation vertical levels. The black lines are the 366 trends of median echo-top height using a 24-hour running mean. Both radars (Fig. 3a and 3c) 367 show clear transition from a mixed cloud regime with low clouds dominant (10 to 22 November), 368 to one dominated by deep convection (22 to 29 November). The onset of deep convection is 369 earlier for S-PolKa ( 22 November) than for C-band radar ( 23 November), consistent with 370 surface rainfall trends. In addition, temporal variations are more gradual in C-band radar 371 observation, similar to [Xu et al., 2015], where low clouds are shown to dominate between 10 372 and 17 November. The echo-top height distributions widen between 18 and 23 November, 373 leading to mostly deep convection after November 23. On the other hand, S-PolKa observations 374 show low-cloud dominating before and after the deep convection period (22 to 29 November). 375 These general trends and subtle differences in observations are well captured in Figs. $3 \mathrm{~b}$ and $3 \mathrm{~d}$, 376 using the site specific large-scale forcing. This indicates the importance of using well377 constrained, radar-specific large-scale forcing for quantitative model validations. 
379 Several discrepancies exist in radar/model comparisons in Fig. 3. First, radar observed echo-top 380 height distributions have larger variability compared with model simulations. For example, S381 PolKa observed MJO mature phase between 23 and 29 November shows co-existing shallow 382 precipitation ( 0 -dBZ echo-top height between $3 \mathrm{~km}$ and $5 \mathrm{~km}$ ) with dominant deep precipitation. 383 Barnes and Houze [2013] also found similar co-existing shallow and deep echo during the MJO 384 mature phase using TRMM PR data. The model simulation in Fig. 3b, on the other hand, shows

385 very little shallow precipitation. Another discrepancy is that the GCE model misses the strongest 386 convection compared with radar observations. This is more prominent in the S-PolKa radar 387 comparison. For example, GCE simulations rarely produce any convection with 0-dBZ echo-top 388 higher than $15 \mathrm{~km}$ (Fig. 3b), which are frequently observed by S-PolKa. This discrepancy 389 becomes more obvious toward the end of the simulation. Another interesting feature that shows 390 prominently in the simulation in Fig. $3 \mathrm{~d}$ is the diurnal cycle during the transition from the 391 suppressed phase to the developing phase (11 to 18 November). The tick marks on the $\mathrm{x}$ axis 392 represent noon time in UTC. During this period, which corresponds to early morning local time, 393 Fig. 3d shows high frequencies ( $>15 \%)$ of low clouds with echo-top heights below the $0^{\circ} \mathrm{C}$ level. 394 Late afternoon sees a much wider cloud distribution and more cumulus congestus and deep 395 convection, with only less than 5\% shallow convection. C-band radar observations in Fig. 3c also 396 show a similar diurnal cycle, but with less amplitude. Similarly, Ruppert and Johnson [2015] has 397 analyzed the S-PolKa radar data and showed diurnal cycles in convective echo-top frequency 398 and area between 13 and 16 November, as shown in Fig. 3a. Model simulation using the Addu 399 forcing, on the other hand, does not show any diurnal cycle during the same period. One possible 400 reason could be that the model is still in its spin-up period. Quantitative details of model 401 simulated diurnal cycles during DYNAMO will be a subject of a future study.

\subsection{Horizontal Structure}

405 In terms of horizontal coverage, it is useful to categorize precipitation into convective and 406 stratiform regions. The convective and stratiform region have distinct vertical structures, 407 dynamics, and diabatic heating profiles [e.g., Houze, 2004]. Their partitioning can also be used 408 as an important criterion for model validations. Figure 4 shows example scenes of observed and 
409 modeled precipitation structures during the November MJO passage over the Addu site. The red 410 area represents convective regions and the green the stratiform. An identical 411 convective/stratiform separation algorithm based on Steiner et al. [1995] was applied to both 412 observations and simulations to ensure accurate comparisons [Powell and Houze, 2013; Rowe 413 and Houze, 2014]. Three snapshots are shown in Fig. 4: on November 18, during the developing 414 phase and on November 23 and 24, during the MJO mature phase. Figure 4 illustrates the 415 transition from isolated convection during the MJO developing phase, to organized convection 416 during the initial period of MJO mature phase, to widespread stratiform rain at its later stage. On 417 November 18, convection was scattered, with a small stratiform region surrounding each 418 convective cell. The GCE model simulation can reproduce the overall structure. The November 41923 time frame in the middle panel has more organized convection, with two large convective 420 areas dominating the scene, and widespread stratiform region trailing them (the systems are 421 moving to the east in general). The GCE simulation shows a well-organized convective line 422 along with a wide stratiform region. However, the convective line consists of some smaller 423 features compared with the larger contiguous convective region observed by S-PolKa. Ten hours 424 later, the system became almost all stratiform, which is also well simulated by the model.

Figure 5 shows temporal variations of domain mean convective and stratiform rainfall rates from radar measurements ( $5 \mathrm{a}$ and $5 \mathrm{c}$ ) and model simulations ( $5 \mathrm{~b}$ and $5 \mathrm{~d}$ ), in order to provide a more quantitative assessment. Both the S-PolKa and C-band radar use the same convective/stratiform separation algorithm [Steiner et al., 1995], but with slightly different thresholds in S-PolKa [Rowe and Houze, 2014] and C-band [Xu and Rutledge, 2014]. Model simulated convective/stratiform separation matches corresponding radar algorithms. Figure 5 shows a good comparison at the Addu site, where the S-PolKa radar observed about $67 \%$ of total rainfall from convection, while the GCE simulated $68 \%$ convective rainfall. The area covered by convective rain is $20 \%$ in S-PolKa radar observations, compared with $26 \%$ in the model (plot not shown). In other words, the simulated stratiform area is less extensive in the simulation, but the rainfall rate agrees with the observation. In terms of temporal evolution, both observations and simulations show that stratiform rain tends to follow rises and falls of convective rain, but with several hours' delay in phase [e.g., Zuluaga et al., 2013]. This is because the stratiform precipitation is the result of organized deep convection. The mesoscale flows that support the widespread stratiform 
440 region develop after convection peaks and organizes. At the Revelle site, Fig. 5d produces much 441 more convective rainfall (89\% of the total rainfall) compared with the observation (72\%). The 442 areal coverage, on the other hand, has better agreement (72\% convective coverage observed by 443 the C-band radar vs. $73 \%$ simulated). These results seem to indicate that in terms of 444 convective/stratiform separation, the GCE model compares better with radar in more intense and 445 organized convection observed at the Addu site. Interestingly, previous CRM simulations have 446 shown similar results. For example, Varble et al. [2011] compared nine CRM simulations of a 447 monsoonal event at Darwin, Australia, during the TWP-ICE field campaign. Similar to our 448 Revelle case, they found that all models underestimated stratiform rainfall rate, despite the fact 449 that some of the models actually overestimated the area of stratiform region. Lang et al. [2007] 450 compared convective/stratiform separation during the TRMM Large-Scale Biosphere451 Atmosphere (LBA) experiment in the Amazon in 1999 using different microphysical packages in 452 the GCE model. Their comparisons with ground radar showed that the stronger, better-organized 453 convection during the easterly wind regime compared better with the observation than the more 454 oceanic, westerly regime case. These previous results are consistent with our DYNAMO case study. For example, the Addu forcing produces stronger, more organized convection, resulting in 456 better model/radar comparisons, similar to the easterly flow case in Lang et al. [2007]. On the 457 other hand, Revelle forcing produces more scattered, less organized convective systems, similar to the westerly flow case in Lang et al. [2007] and the Varble et al. [2011] monsoonal case, where the models overestimated convective rain. In conclusion, the GCE model can reproduce subtle differences in convection organization at the Addu and Revelle sites. On the other hand, it also inherited limitations and discrepancies in validating with less organized convection using 463

464 The sizes of contiguous precipitating area are correlated with rainfall intensity [Ruppert Jr. and 465 Johnson, 2015] and is used as an indicator of the degree of convection organization [Rowe and 466 Houze, 2014; Xu et al. 2015] Xu et al. [2015] analyzed precipitation feature sizes measured by 467 surface radars during the DYNAMO campaign by defining a precipitation feature as the region 468 with contiguous radar reflectivity greater than 15 and $20 \mathrm{dBZ}$, respectively. Our study follows 469 this method, but uses $17 \mathrm{dBZ}$ as the threshold to be consistent with the minimum TRMM PR 470 reflectivity. The effective size shown in Fig. 6 is defined as the square root of the total area of 
471 each feature. Time series of the effective feature size distributions are shown in Fig. 6a for S472 PolKa observations and Fig. 6b for GCE simulations using Addu forcing. Fig. 6c and 6d are for 473 the C-band observations and model simulations using Revelle forcing. In all four panels, 474 precipitation feature sizes increase with increasing echo-top heights and surface rainfall rates, a 475 trend also described for all three DYNAMO MJO events by Rowe and Houze [2015]. The total 476 numbers of features (shown in red dots in Fig. 6) tend to increase with feature size, too, although 477 increases in feature numbers usually occur ahead of increases of feature sizes. This indicates that 478 deep convection tends to start individually and later organizes themselves into larger convective 479 systems, as shown also in Fig.5 and described by Rowe and Houze [2015]. Very large feature 480 sizes appear with high frequency during the MJO mature phase, again indicating enhanced 481 convection organization. Comparing S-PolKa (6a) and C-band radar (6c) observations during the 482 MJO mature phase (21 to 30 November), we find that S-PolKa (6a) observed higher frequencies 483 of both the very large feature size (more than $40 \mathrm{~km}$ ) and very small feature size (less than $5 \mathrm{~km}$ ) 484 compared with C-band radar observations (6c). The high frequencies of the very large features 485 are consistent with the previous conclusion that the Addu site has more organized convective 486 systems and more stratiform rain. GCE simulations using both Addu forcing (Fig. 6b) and 487 Revelle forcing (Fig. 6d) can reproduce temporal variations of the observed convective feature 488 489 sizes. However, both simulations overestimate feature sizes. The largest discrepancy occurs during the mature stage when the mean feature size peaks. This shows that the model has overorganized convection within the domain. Previous studies have shown that the low-level wind 492 forcing provides only domain mean wind field, it may have discouraged random convection from 493 developing in these simulations. In addition to using $17 \mathrm{dBZ}$ as the threshold for precipitation 494 features, we have tested an alternative algorithm where the convective/stratiform separation was 495 used. For example, the contiguous convective region was defined as a "convective feature". This 496 later method resulted in smaller feature sizes, but all conclusions remain the same as shown in 497 Fig. 6. After deriving both the vertical extents and horizontal sizes of precipitation features, the natural 500 next step is now to examine their relationship. For every precipitation feature identified, we tally 501 its effective length and the maximum radar echo-top height. Fig. 7 shows contours of the joint 
502 probability density function for S-PolKa radar observations (7a), GCE simulations using Addu 503 forcing (7b), C-band radar observations onboard Revelle (7c), and GCE simulations using 504 Revelle forcing (7d). Large feature size is a sufficient condition for high radar echo-tops, but it is 505 not necessary in all four cases. This is because large-size features generally consist of many 506 individual convective elements at various development stages, with at least some of them being 507 deep. On the other hand, many relatively small, isolated deep convection do reach the tropopause. 508 Among the four panels in Fig. 7, the S-PolKa observations have by far the largest amount of 509 precipitation features with their echo-top heights above $15 \mathrm{~km}$, extending to $20 \mathrm{~km}$, while the 510 simulations in Fig. $7 \mathrm{~b}$ and $7 \mathrm{~d}$ have few. The C-band observations also shows some precipitation 511 features above $15 \mathrm{~km}$, but with less frequency compared with S-PolKa. The model simulated 512 feature size vs. maximum echo-top height are shown in Figs. 7b and 7d. For small features with 513 effective length less than $30 \mathrm{~km}$, simulated maximum echo-top height distributions agree 514 reasonably well with observations, especially at the Revelle site. However, the Addu site 515 simulations are missing all features with echo-top height above $15 \mathrm{~km}$. The biggest discrepancy 516 exists for large precipitation features, e.g., features with effective lengths longer than $70 \mathrm{~km}$. For 517 example, for an S-PolKa observed feature with $100 \mathrm{~km}$ effective length, the echo-top heights 518 range between $13 \mathrm{~km}$ and $20 \mathrm{~km}$, whereas the GCE simulated height ranges are between $10 \mathrm{~km}$ 519 and $15 \mathrm{~km}$. Similar discrepancies also exists at the Revelle site. Given the fact that the simulated 520 mean surface rainfall agrees well with the observations, and that previous studies show CRMs 521 overestimating updraft strengths in deep convection with the TWP-ICE case study [Varble et al., 522 2014; Wu et al., 2009], we speculate that the underestimation of echo-top heights in CRMs may 523 be due to the model deficiency in ice-phase microphysical processes or numuerical damping 524 issues. Sensitivity tests are carried out in section 5 to test these hypotheses.

\subsection{Comparisons with TRMM Precipitation Radar}

528 Ground-based radar has the advantage of continuous coverage with a high spatial resolution. 529 However, it has limited spatial coverage. The space-borne radar, e.g., the TRMM PR 530 precipitation radar and CloudSat radar, has a global coverage, but with limited sampling 531 frequencies at a fixed location. For example, the NSA area shown in Fig. 1 has only 2 to 3 532 TRMM overpasses per day, far less than the 10- to 15-minute interval of ground-based scanning 
533 radar. Space-borne radar also has lower sensitivity compared with the ground-based radar. 534 During DYNAMO period, CloudSat radar did not collect much data due to a battery malfunction. 535 In this section, we compare GCE model simulation with the TRMM PR data using a similar 536 methodology as in sections 3.2 and 3.3 .

538 To ensure a fair comparison, we performed the third set of simulations using NSA large-scale 539 forcing derived from the four sounding stations in the NSA. The TRMM PR scanning data are 540 used if at least one contiguous data point is located within the NSA box. In other words, the 541 TRMM sampling domain is larger than the NSA box, although at least part of the precipitation 542 feature must locate within the NSA. Figure 8 compares 17-dBZ radar echo-top height 543 distributions (upper panel) and the same variable simulated by the GCE model. Again, the 544 TRMM PR radar simulator is used to derive radar reflectivity from the GCE model simulation. 545 The low temporal resolution in TRMM PR is obvious in Fig. 8a. Also, due to TRMM PR's low 546 sensitivity, the 17-dBZ echo-top height distributions are contaminated by the large amount of 547 data points cluttered near the radar bright band caused by melting ice-phase particles. It is 548 difficult to use TRMM PR data quantitatively for this single case study, as shown in Fig. 8, 549 because of the high noise level. However, the observations and model agree qualitatively in 17$550 \mathrm{dBZ}$ echo-top height distributions. The convection is dominated by low clouds with $17 \mathrm{~dB}$ echo551 top height below the melting level during the suppressed phase of MJO (10 to 15 November). At 552 the mature phase (24 to 28 November), these low clouds occur significantly less. GCE simulated 553 TRMM PR data in Fig. 8b still use the hourly data output from the model. It shows that the 17$554 \mathrm{dBZ}$ echo-top height almost completely missing below $5 \mathrm{~km}$ between 24 and 28 November, 555 indicating exclusive deep convection and widespread deep stratiform rain. The temporal 556 variations of the median echo-top height (black lines in Fig. 8) do show variations around the 557 melting level, but the amplitudes are much smaller than surface-based radar observations in Fig. 5583.

559

560 The simulated precipitation feature sizes are also compared with TRMM PR data. Due to limited 561 temporal resolution of TRMM PR, all features are aggregated over the 30-day simulation period 562 to show the probability distributions of the precipitation feature sizes in Fig. 9. The black line is 563 the TRMM observation and the red line is the GCE simulation. Precipitation features with sizes 
564 less than $50 \mathrm{~km}^{2}$, which correspond to about two PR sampling points, are not considered. In 565 general, the distributions agree very well between the observations and simulations, both of 566 which peak at around $80 \mathrm{~km}^{2}$ size and drop off quickly toward large-size features. The 567 simulation slightly overestimates medium features around $200 \mathrm{~km}^{2}$ size and underestimate 568 features larger than $1000 \mathrm{~km}^{2}$. When the feature size becomes large, the probability of the feature 569 intercepting with the edge of either the TRMM PR swath or model lateral boundaries increases. 570 The sizes of these edge features are simply counted as they are. This means that the feature size 571 distribution is biased at the large tail of the size spectrum and only represents the distributions 572 within the sampling swath. However, the comparison remains meaningful because the model 573 domain $(256 \mathrm{~km})$ is comparable to the TRMM swath width $(250 \mathrm{~km})$.

575 Similar to Fig. 7, correlations between 17-dBZ precipitation feature size and its maximum echo576 top heights for each feature are plotted in Fig. 10. It generally confirms the conclusion drawn 577 from Fig. 7. Good comparisons between the TRMM PR observations and the GCE simulation 578 exist for features with effective lengths less than $50 \mathrm{~km}$. The simulation again misses the 579 strongest radar echo-top heights for very large features.

\section{4. Model Inter-comparison}

583 Three different CRMs: GCE, SAM and WRF, are used in model inter-comparisons in this 584 section. The NSA large-scale forcing is used for these simulations in order to represent 585 precipitation variations over the large area covered by the four sounding stations. The 586 simulations have been coordinated to use the same specifications as much as possible to reduce 587 uncertainties in results (Table 1). The matching radar observation for NSA forcing is the TRMM 588 PR data, as shown in section 3.4. However, TRMM data suffer from low sensitivity of $17 \mathrm{dBZ}$. 589 In order to avoid losing information at less than $17 \mathrm{dBZ}$ reflectivity regime, we focus on 590 presenting only model results in this section. Figure $2 \mathrm{c}$ shows surface rainfall comparisons 591 among three CRMs (colored lines), together with forcing derived surface rainfall (the black line). 592 Different model simulations agree with one another very well. The GCE model using the 593 Morrison scheme is not plotted in Fig. 2c because it is almost identical to the GCE 3-ICE scheme 594 simulation. When compared with forcing-derived surface rainfall, models generally agree better 
595 with observations when rainfall rates are high and the forcing is strong, but miss some of the 596 peaks during the suppressed and transition period. This could be because of the large 597 uncertainties when the large-scale forcing is weak. Johnson et al. [2015] have compared the 598 forcing-derived surface rainfall with TRMM 3B42 product, as well as several other global 599 surface rainfall products, and found good agreements among the observations during the 600 DYNAMO period. The rest of this section will again focus on precipitation structure 601 comparisons. Since we are only comparing model results in this section, the Rayleigh 602 assumption is used to calculate radar reflectivity for its simplicity.

604 Figure 11 shows time series of 0-dBZ echo-top height distributions for the four sets of 605 simulations. The GCE model uses both Goddard 3-ICE scheme (Fig. 11a) and Morrison two606 moment scheme (Fig. 11b). The SAM (Fig. 11c) and WRF (Fig. 11d) model simulations both 607 use the Morrison scheme. In general, temporal variations of echo-top height distributions agree 608 well among all simulations. The median echo-top heights, shown as black lines with 24-hour 609 running mean, correlate well with one another. They demonstrate a clear transition from low 610 clouds dominating the suppressed stage (10 to 15 November), to the more diverse and evenly 611 distributed cloud heights during the developing stage (16 to 21 November), where low, middle 612 and high clouds coexist. Deep clouds dominate the mature stage (22 to 27 November) with the 613 shallow clouds population almost completely missing, and large areas of deep stratiform cloud 614 deck present. This shows the robustness of different CRMs in simulating precipitation structures 615 when they are constrained by the same observed large-scale forcing. Compared with simulations 616 using radar site specific large-scale forcing in Fig. 3, NSA forcing produces more robust and 617 gradual, less episodic distributions, probably because the NSA domain is about five times the 618 size of individual radar domains. Averaging over the large domain results in smoother temporal 619 variations. This again indicates the importance of matching large-scale forcing location with 620 observation domain for model validations. On the other hand, comparing simulations using NSA 621 forcing and using Addu/Revelle forcing also indicates that the former is more desirable in terms 622 of reproducing robust MJO phase change signals. Subtle differences still exist among different 623 models. For example, the small fraction of convection that reaches above $12 \mathrm{~km}$ is largely 624 missing in Fig. 11b, but appears with more frequency for other simulations. In general, GCE 625 model simulates less frequencies of these deep convection compared with both the SAM and 
626 WRF model. On the other hand, the SAM model (Fig. 11c) has lower echo-top heights during 627 the suppressed phase, and the transition from the low clouds to mixed clouds seems to be more 628 abrupt, compared with the other two models.

630 Precipitation feature sizes and their temporal variations are shown in Fig. 12. The black lines 631 represent median feature sizes, and the red lines represent the total feature number. Figure 12 632 again shows consistent temporal variations in terms of feature sizes. Compared with the episodic 633 structures in Fig. 6, NSA forcing produces a clearer transition from the suppressed to active 634 phase in the horizontal structures. During the suppressed phase and at the beginning of the 635 developing phase (10 to 17 November), all precipitation feature sizes remain less than $20 \mathrm{~km}$, 636 indicating small, scattered convection. The echo-top height distributions in Fig. 11, on the other 637 hand, show that starting from November 15, deep convection has already started to develop. The 638 precipitation features remain small and scattered for an additional day or two before starting to 639 increase in sizes on November 17. This is an indication that the convection starts to organize 640 only after 1 2 day of the onset of medium to deep convection. Features larger than $60 \mathrm{~km}$ in 641 sizes mainly appear during the mature phase (22 to 27 November), representing well-organized 642 convective systems. The largest precipitation features occurred between 24 and 25 November, 643 when occasionally the whole domain consists of one or two contiguous features. They were 644 labeled as missing data in the plots, as shown by the gaps around that period. Despite general 645 similarities among different CRMs, GCE produces larger sizes and fewer precipitation features 646 compared with both SAM and WRF simulations during the suppressed phase. On the other hand, 647 the WRF model has the smallest feature sizes and the highest total feature number during the 648 suppressed and developing stage between 12 and 21 November.

\section{5. Sensitivity Tests}

652 All model simulations discussed so far used the domain size of $256 \mathrm{~km}$ x $256 \mathrm{~km}$. One thing we 653 have not addressed is matching model domain sizes with the area size where the large-scale 654 forcing is derived. While the $256 \times 256 \mathrm{~km}$ domain matches the single-radar sampling diameter $655(\sim 300 \mathrm{~km})$, it is much smaller than the NSA sounding array size of $830 \mathrm{~km} \times 770 \mathrm{~km}$. The small 656 domain used in section 4 for NSA forcing may have limitations in representing some of the 
657 mesoscale convective systems, especially during the mature stage of the MJO, when some of the 658 observed mesoscale convective systems have physical sizes larger than the $256 \mathrm{~km}$ domain size 659 (cf. Fig. 4). This could produce low biases in simulated feature sizes since compensating updrafts 660 and downdrafts must be balanced within the limited domain, possibly limiting the largest of 661 feature sizes. Small model domain size and a coarse vertical resolution both could affect echo662 top height distributions and their temporal variations with MJO phases. In order to address these 663 uncertainties, we conduct additional sensitivity tests using GCE model with the Goddard 3-ICE 664 microphysical scheme and the NSA forcing. The small domain simulation uses the same $256 \times$ $665256 \mathrm{~km}$ size as in section 4, but with a coarser vertical resolution of 45 levels, instead of 106 666 levels as used in model inter-comparisons. The large-domain simulation has the dimension of $6671024 \times 1024$, also with 45 vertical levels. The horizontal resolution remains the same as $1 \mathrm{~km}$. 668 The vertical levels are also stretched, with the nominal resolution of $0.5 \mathrm{~km}$ at the middle 669 troposphere.

670

671 Figure 13a and 13b show distributions of the 0-dBZ echo-top heights for the small- (Fig. 13a) 672 and large- (Fig. 13b) domain simulation. The median echo-top heights, shown as the black lines, 673 again correlate with each other well, with clearly defined suppressed, developing and mature 674 stages. These results suggest that the GCE simulation with $0.5-\mathrm{km}$ vertical resolution can 675 produce similar general cloud distribution characteristics as the higher resolution of $0.25 \mathrm{~km}$. 676 However, it does so with more noise and less confidence compared with both higher vertical 677 resolution and larger domain size simulations. The increased sample size in the large domain 678 simulation (Fig. 13b) produces much smoother temporal variations in echo-top height 679 distributions compared with Fig. 13a. For example, during the suppressed phase on November 680 12, there is a strong deep convective event that dominates in Fig. 13a, resulting in a spike in the 681 median echo-top height. The big domain simulation, on the other hand, can still maintain enough 682 shallow clouds so that the median echo-top height remains low. When comparing Fig. 13a with 683 the small-domain, fine vertical resolution simulation in Fig. 11, the later again shows less noise. 684 The local maximum on November 12 is less prominent in all panels in Fig. 11 compared with 685 Fig. 13a. This suggests that insufficient vertical resolution could lead to spurious strong 686 convection under certain circumstances, possibly because of biases in parameterized turbulent 687 mixing and its sensitivity to grid sizes. 
689 Another set of sensitivity tests are designed to explore possible causes of models' 690 underestimation of echo-top height in deep convection (e.g., Fig. 3). Note that these sensitivity 691 tests may not be physically realistic, but serve the purpose of isolating and elucidating possible 692 physical mechanisms that may affect echo-top heights. Three possible mechanisms have been 693 identified: reducing graupel sizes, removing spurious cloud evaporation, and raising damping 694 layers at the top boundary. In deep convection, graupel is the dominant hydrometeor species 695 contributing to radar reflectivity at upper levels. In a bulk microphysical scheme, graupel size 696 distributions are assumed to be either exponential or gamma. These assumptions are empirical 697 and often have large uncertainties. The working hypothesis is that, reducing graupel's mean sizes 698 reduces their terminal fall velocities accordingly. As a result, graupel particles could be lifted to 699 higher levels by the same updrafts, increasing simulated radar echo-top heights. To test this 700 hypothesis, the intercept parameter for the assumed exponential graupel size distribution in the 701 Goddard 3ICE scheme was doubled in the first sensitivity test. The resulted echo-top height 702 distributions are shown in Fig. 13c. Compared with Fig. 13a, Fig. 13c has very little change. This 703 test suggests that graupel size uncertainties in microphysical scheme are not likely reasons for 704 the underestimation of deep echo-top heights.

The previous sensitivity test shows that reducing hydrometeors' terminal fall velocity does not 707 help in increasing cloud echo-top heights in the current case study. A natural speculation follows 708 is that the strengths of the updraft cores in deep convection might be too weak. Cloud-scale 709 vertical motion are not observed during DYNAMO, but we can design sensitivity tests with a 710 CRM to increase simulated updraft velocities. Two experiments, one changes microphysics, the 711 other changes the numeric, are carried out in this section. The first experiment reduces the so712 called spurious evaporation, which is produced by artificial effect of cloud boundaries advecting 713 through a Eulerian grid where excessive evaporation may be produced [Klaassen and Clark, 714 1985; Grabowski and Morrison, 2008; Lang et al., 2014]. The cooling generated by the spurious 715 evaporation could act to damp deep convection. In the GCE sensitivity test, a condition has been 716 added that the cloud droplets/ice does not evaporate/sublime, even in unsaturated environment, 717 when the vertical air velocity is higher than $0.5 \mathrm{~m} / \mathrm{s}$. The reduces the evaporation at cloud edges 718 where cloudy scene occupies only part of the numerical grid [Lang et al., 2014]. The resulted 
719 echo-top heights are shown in Fig. 13d. Reducing spurious evaporation indeed resulted in 720 increased echo-top heights, by an average value of about $2 \mathrm{~km}$. However, there are still little 721 convection that reached above $15 \mathrm{~km}$. On the other hand, reduced evaporation also invigorated 722 shallow convection, especially during the suppressed period. The high frequency of shallow 723 convection with echo-top heights between 1 and $4 \mathrm{~km}$ on November 4 , and between November $724 \quad 10$ and 15 are significantly reduced, resulting in unrealistic temporal variations of echo-top 725 heights compared with radar observations. In conclusion, although artificially removing spurious 726 cloud evaporation produced taller deep convection, it also invigorates shallow convection during 727 the suppressed MJO phase which is unreailistic. Therfore this is not the main reason for the 728 CRM deficiency. The next experiment in the attempt to increase vertical velocity involves 729 raising the numerical damping layer near the upper boundary from $18 \mathrm{~km}$ to $22 \mathrm{~km}$. This 730 damping layer is needed in CRMs to absorb vertically propagating gravity waves. However, 731 excessive damping at upper levels sometimes results in weakened updrafts, especially at higher 732 levels. The model results, as shown in Fig. 13e, are again very similar to the control study shown 733 in Fig. 13a, indicating that upper level damping is not the reason for underestimation of echo-top 734 heights.

736 To summarize, all simulations, with different forcing, different models and microphysics, as well 737 as different vertical resolutions and domain sizes, have reproduced observed cloud population 738 characteristics and the timing of transitions from the suppressed, to developing, to the mature 739 phase of the November MJO event. However, they show different noises and offer different 740 confidence level when interpreting the results. For CRM simulations using large-scale forcing, it 741 is recommended that the domain size should in general match the area covered by the sounding 742 array, in order to better carry out the model/observation comparisons. Higher vertical resolution 743 is also desirable in reducing the noise level in echo-top height variations and providing more 744 details in its distributions. Three sensitivity tests designed to increase radar echo-top heights in 745 deep convection failed to identify reason(s) for the underestimation of cloud echo-top heights. 746 Instead, these results suggest that uncertainties in cloud microphysics, as well as upper level 747 numerical damping, are unlikely to be the underlying mechanisms. Future study will focus on 748 investigating convection-circulation feedbacks in the Tropics and their impacts on limited-area 749 models driven by large-scale forcing. 
751 In terms of horizontal extent of simulated precipitation features, the large-domain simulation has

752 added a small amount of larger than $256 \mathrm{~km}$ precipitation features. Figure 14 shows the scatter

753 plot of the 17-dBZ effective feature lengths vs. the maximum echo-top heights for every 754 precipitation feature. Figure $14 \mathrm{a}$ and $14 \mathrm{c}$ are for the two small-domain simulations with $0.5 \mathrm{~km}$ 755 (Fig. 14a) and $0.25 \mathrm{~km}$ (Fig. 14c) vertical resolution, respectively. The largest feature size in 756 these two panels is roughly the same as their domain size of $200 \mathrm{~km}$. The main sensitivity to the 757 vertical resolution is that higher vertical resolution in Fig. 14c can simulate shallow precipitation 758 with high rainfall rates, as shown by the points below $4 \mathrm{~km}$. These points are missing with the 759 45-level simulation in Fig. 14a. However, this does not necessarily mean that there is no shallow 760 precipitation in the coarser vertical resolution simulation; they just did not make the threshold of $76117 \mathrm{dBZ}$ (figure not shown). In other words, the coarser resolution simulation produces weaker 762 shallow convection compared with its finer vertical resolution counterpart. When the $1024 \mathrm{~km} \mathrm{x}$ $7631024 \mathrm{~km}$ domain is used, maximum precipitation feature size increases to $370 \mathrm{~km}$ (Fig. 14b), 764 comparable to the largest size observed by TRMM PR (Fig. 14d). As in all GCE simulations 765 using NSA forcing (and to a lesser extent for both SAM and WRF simulations), the deepest 766 convection with echo-top height above $15 \mathrm{~km}$ is again largely missing. The large features have 767 768 their maximum 17-dB echo-top heights centered at around $12 \mathrm{~km}$, whereas TRMM PR shows 771

\section{6. Model and Radar Cross Validations}

774 Comparisons between multiple model simulations and radar observations have demonstrated that 775 the three CRMs can robustly reproduce structural characteristics of precipitation at different 776 MJO phases and their temporal evolution. Furthermore, subtle differences shown at different 777 radar sites for the same MJO event are well captured by models when constrained by the site778 specific large-scale forcing. After achieving positive results in model validations, we now focus 779 on the third goal of this study: to quantify inter-model and inter-radar discrepancies in 
780 precipitation structures in order to guide better interpretations of model simulations and radar 781 observations.

783 Two variables are used to quantify vertical distributions of radar echo-top heights: correlation 784 coefficients of the median echo-top heights, representing their temporal variations as the MJO 785 progresses, and differences between the mean of the time series. Figure 15 summarizes scatter 786 plots of these two variables for various pairs of observations/simulations. All correlation 787 coefficients are calculated with strictly matched time stamps. A high correlation coefficient 788 combined with a small mean difference suggest a good agreement. In Fig. 15, circles represent 789 model-model comparisons; squares represent model-observation comparisons; and the triangles 790 are radar-radar comparisons. Simulations constrained by the same large-scale forcing are shown 791 in warm-colored circles, whereas purple circles represent GCE simulations using different large792 scale forcing. The label for each point indicates the single parameter that differs. For example, 793 the purple circle labeled "NSA/Revelle" represents the comparison between two GCE model 794 simulations with identical setups otherwise, but one using NSA forcing, the other using Revelle 795 forcing. Model sensitivity tests are clustered in two groups: the warm-colored ones at the high 796 correlation/small difference corner, and the purple ones on the low correlation side. This shows 797 that using the specific large-scale forcing derived for the observation site is of the first order 798 importance for accurately representing temporal variations of echo-top heights. Among the 799 warm-colored circles, red circles compare three different models, all using the NSA forcing. 800 SAM and WRF agree better on the mean echo-top heights, whereas GCE and WRF agree better 801 in terms of temporal variations. The main cause of differences in echo-top heights is that the 802 GCE model has higher echo tops compared with the other two during the suppressed phase 803 between 10 to 15 November (cf. Fig. 11). For shallow convection, two factors might contribute 804 to the differences: surface fluxes and the sub-grid mixing schemes (cf. Table 1). Additional 805 studies are needed to clarify the causes. Figure 15 also shows sensitivities using the GCE model. 806 Switching microphysical schemes from Goddard 3-ICE to Morrison scheme has a small effect on 807 simulated precipitation structures, with the correlation coefficient above 0.9 and the mean echo808 top height difference of $0.1 \mathrm{~km}$. Increasing GCE's vertical resolution mainly affects echo-top 809 heights (mean differences of $0.7 \mathrm{~km}$ ), but not on their temporal variations ( $>0.9$ correlation 810 coefficient). On the other hand, when model domain size increases, the main impact is on 
811 temporal correlations. This information can potentially guide future modeling studies. For 812 example, modelers often face choices when they cannot have both large-domain and high813 resolution at the same time due to computational constraints. Figure 15 indicates that increasing 814 vertical resolution should be chosen if accurate simulations of the cloud vertical structure is the 815 goal. However, in order to achieve robust temporal variations, one should first consider using a 816 large enough domain.

818 The squares in Fig. 15 show comparisons between model simulations and radar observations. 819 Blue squares are comparisons between C-band radar observations and the Revelle forcing 820 simulations; green squares are between S-PolKa observations and the Addu forcing simulation. 821 S-PolKa radar observations and Addu forcing simulation have slightly better correlation at 0.53 , 822 compared with 0.38 for the C-band observations and Revelle forcing simulation. The fact that 823 they are all lower than correlation coefficients among model sensitivity tests indicates that, for 824 our future sensitivity studies, the choices of model/microphysical scheme/domain/vertical 825 resolution likely will not affect results pertaining to temporal variations of echo-top heights, at 826 least to the extent that can be meaningfully verified by surface radar observations.

828 The consistency in model performances encourages us to try to corroborate radar observations 829 with model simulations. The challenge here is that the S-PolKa radar-observed 0-dBZ echo-top 830 heights have a dependency on data range due to the coarse vertical resolution when using the 831 SUR scanning mode. This is because radar beam widens with distances. When reflectivity data 832 were re-gridded, larger uncertainties exist at locations farther away from the radar site, especially 833 for limited elevation angles during the S-PolKa SUR scanning. Three different ranges for radar 834 observations are shown in Fig. 15: the full dataset with the range between 0 and $150 \mathrm{~km}$, "range 8351 " with data located between $20 \mathrm{~km}$ and $120 \mathrm{~km}$, and "range 2" with data between $20 \mathrm{~km}$ and $836100 \mathrm{~km}$. The reason for using $20 \mathrm{~km}$ as the minimum range is because the radar cannot detect the 837 actual echo top of deep convection within the close range. There are two sets of radar/radar 838 comparisons: S-PolKa SUR (SPol) vs. C-band Revelle radar (C-band) at different locations, and 839 S-PolKa's two different scanning strategies (SPol vs. RHI in Fig. 15). For the C-band 840 observations, the average echo-top height decreases slightly from $6.13 \mathrm{~km}$ for the full dataset, to $8416.10 \mathrm{~km}$ for the $20 \sim 120 \mathrm{~km}$ range, to $6.05 \mathrm{~km}$ for the $20 \sim 100 \mathrm{~km}$ range. For the S-PolKa data, 
842 they are much larger at $6.90 \mathrm{~km}, 6.47 \mathrm{~km}$ and $6.09 \mathrm{~km}$, respectively. This is the main reason for

843 the vertical spread of the green squares. Model simulations consistently show smaller differences

844 than the S-PolKa-observed range of mean echo-top height. If we assume the model simulation is

845 correct, we can deduce that data subset which has the best model-radar comparison is the most

846 accurate representation of the true 3D reflectivity field. According to Fig. 15, this is "range 2"

847 data, subset between $20 \mathrm{~km}$ and $100 \mathrm{~km}$. This conclusion can be also verified independently

848 using the multi-radar/multi-model strategy presented in this study, as well as by the same S-

849 PolKa radar with its two different scanning methods, labeled as SPol/RHI in Fig. 15. Assuming

850 model simulations were accurate, the simulated differences between Addu forcing and Revelle

851 forcing should match the observed differences by S-PolKa and the independently measured C-

852 band radar. This is exactly the case for "range 2" data shown in Fig. 15, in the pair of points

853 labeled as "Addu/Revelle" and "SPol/C-band Range 2". For SPol/RHI comparisons, the

854 temporal correlations are all around 0.7, showing a high degree of consistency in the temporal

855 variations measured by the two different sampling methods. They are higher than the squares in

856 Fig. 15, which represent model and radar comparisons, with correlation coefficients between

8570.35 and 0.5 . In other words, model simulated temporal variations in echo-top heights can be

858 further improved using radar observations. In terms of the mean echo-top height, the differences

859 between SUR and RHI scanning range from $0.6 \mathrm{~km}$ for the full scan, to $0.2 \mathrm{~km}$ for $20 \sim 100 \mathrm{~km}$

860 scan range 2. The least difference between SPolKa SUR scan and RHI scan (SPol/RHI) is for

861 range 2 data, the same conclusion drawn when using radar/model comparisons. The decision of

862 using range 2 subset for echo-top height comparisons for both S-PolKa and C-band radar is

863 based on cross validation results presented in this section.

864

\section{7. Summary}

866

867 The unique aspect of the current study is its use of observations from three radars and three

868 CRMs driven by radar site-specific large-scale forcing to study the temporal variations of 869 precipitation structures, both vertically and horizontally, during the DYNAMO November MJO 870 event. Observations from the S-PolKa radar at Addu Atoll, TOGA C-band radar onboard R/V 871 Roger Revelle, and the space-borne TRMM PR, simulations by cloud-resolving models GCE, 872 SAM and WRF, and three large-scale forcing derived for the two ground-based radar sites at 
873 Addu and Revelle, and over the NSA, were compared within a consistent framework of radar 874 data analysis, modeling, and model validations. Sensitivity of the GCE model to microphysical 875 schemes and processes, domain sizes, and vertical resolutions were also tested.

877 The study emphasizes how precipitation structures change as an MJO event evolves, which is 878 closely related to variations of diabatic heating and the moisture budget during the MJO event. 879 Two direct radar measurables, the 0-dBZ echo-top height and the $17 \mathrm{dBZ}$ precipitation feature 880 size, were used to quantify precipitation structures. The largest uncertainty inherent in these 881 measurables was radar's sampling sizes and scanning strategies, as discussed in section 6. 882 Frequency distributions of the echo-top heights represented the intensity of convection, and the 883 feature sizes indicated the degree of organization of convection. A radar simulator was used to 884 calculate radar reflectivity for both the $\mathrm{C}$ - and $\mathrm{Ku}$-band radar to ensure accurate comparisons. 885 During the DYNAMO period, global MJO signals were characterized by the Real-time 886 Multivariate MJO (RMM) indices [Wheeler and Hendon, 2004]. The current study categorized 887 DYNAMO MJO phases in the Indian Ocean into four stages according to local cloud structures 888 observed by radar: (1) The period from November 1 to 9, which corresponded to the global 889 analysis of RMM phases 4, 5, and 6, represented the gap phase where the peak precipitation has 890 moved out of the Indian Ocean. Precipitation was characterized by moderate rainfall with a 891 mixture of low, medium and high clouds and a relatively small amount of organized convection.

892 (2) November 10 to 16 was the suppressed phase (RMM phases 7 and 8) where the rainfall rate 893 was low and convection was dominated by scattered shallow precipitation within the NSA. (3) 894 During the MJO developing phase from November 17 to 23 (corresponding to RMM phase 1), 895 surface rainfall and echo-top heights started to increase. Precipitation had a mixture of 896 convection with different heights. Some convection also started to organize, forming larger 897 precipitation features. (4) The mature phase spanned from 24 to 30 November (corresponding to 898 RMM phases 1, 2 and 3). At the mature stage, deep clouds dominated and eventually organized 899 into large contiguous features. At the later stage of the mature phase, stratiform cloud decks 900 dominated the scene. These common characteristics were consistent with previous studies and 901 showed robustly in all radar observations and model simulations during the DYNAMO 902 November MJO event. 
904 Another goal is to take advantage of the multi-radar, multi-model framework to identify subtle

905 differences in precipitation structures at different locations: with S-PolKa and C-band radar near 906 the equator, roughly $825 \mathrm{~km}$ apart at the two southern corners of the NSA, and TRMM PR 907 covering the whole NSA domain. This provides a new opportunity for additional model 908 validations and cross-comparisons. For example, compared with the C-band radar, the S-PolKa 909 radar observed more deep convection and higher mean echo-top heights for the entire November 910 MJO event. Convection at the S-PolKa site was also more episodic. During the MJO mature 911 stage, higher frequencies of large precipitation features and higher percentages of stratiform 912 coverage were observed at the S-PolKa site, compared with the C-band site. These subtle 913 differences were all captured reasonably well by the GCE model when site-specific large-scale 914 forcing was used, and when the matched convective/stratiform separation algorithms were used 915 for both the simulations and observations. TRMM PR has limited temporal sampling within the 916 NSA. However, model simulations using NSA forcing compared well within TRMM PR's 917 detection threshold, both in terms of radar echo-top heights and distributions of precipitation 918 feature sizes. On the other hand, certain systematic errors still existed for all model simulations. 919 For example, the models missed the deepest convection, especially during the mature stage 920 within large precipitation features. This needs to be investigated in the future.

921

922 The multi-radar, multi-model cross comparisons provided by the DYNAMO field campaign not 923 only increased our confidence in both observed and simulated precipitation structures during the 924 November MJO event, they also provided a unique opportunity to explore uncertainties in 925 different radar scanning strategies and how they affected model/radar comparisons. As shown in 926 this study, echo-top heights observed by the S-PolKa radar strongly depended on sampling 927 ranges due to its limited sampling. Combining C-band observations and model simulations, we 928 have identified S-PolKa subset data with a $20 \mathrm{~km}$ to $100 \mathrm{~km}$ sampling range as the best match, 929 and subsequently used the results to help model validations. 


\section{Acknowledgment:}

937 This study is mainly funded by Grant DE-SC0008568 of the US Department of Energy, Regional and Global Climate Modeling Program and Atmospheric System Research Program. X. Li would

939 like to acknowledge additional funding from NASA grant NNX13AQ29G. S. Wang

940 acknowledges support from National Science Foundation under grants AGS-1062206, AGS-

941 1305788, and AGS-1543932. W.-K. Tao is also supported by the NASA Precipitation

942 Measurement Mission (PMM) and NASA Modeling Analysis and Prediction (MAP) program.

943 Both S-PolKa and C-band radar data are archived at DOE ASR's data site

944 https://asr.science.energy.gov/data. TRMM PR data can be obtained through NASA website

945 https://pmm.nasa.gov/data-access/downloads/trmm. The model simulations are archived on DOE

946 server http://portal.nersc.gov/project/cpmmjo and NASA's mesoscale model webserver

947 https://cloud.gsfc.nasa.gov. The RMM index is from www.bom.gov/au/climate/mjo/. Drs.

948 Shaocheng Xie and Yunyan Zhang from Lawrence Livermore National Lab, and Dr. Paul

949 Ciesielski from Colorado State University provided large-scale forcing data and many insights in

950 the interpretations. We would also like to thank Dr. Samson Hagos at PNNL for his help in

951 archiving data. Dr. Zhe Feng at PNNL and Prof. Courtney Shumacher at Texas A\&M provided

952 valuable suggestion on using surface-based radar data. Acknowledgment is also made to the

953 NASA Center for Climate Simulation, NASA Advance Supercomputing Division, and NASA

954 Precipitation Processing System, for resources used in this research. PMEL Contribution \# 4684

955 (CZ).

956

957

958

959

960

961

962

963

964

965

966

967

968

969

\section{Reference:}

Ahmed, F., C. Schumacher, Z. Feng, and S. Hagos (2016), A retrieval of tropical latent heating using the $3 \mathrm{~d}$ structure of precipitation features, J. App. Meteor. Clim., 55, 1965-1982.

Anber, S., S. Wang, and A. H., Sobel (2014), Response of atmospheric convection to vertical wind shear: cloud resolving simulations with parameterized large-scale circulation. Part I: Specified radiative cooling. J. Atmos. Sci. 71, 2976-2993.

Barnes, H. C., and R. A. Houze (2013), The precipitating cloud population of the Madden-Julian Oscillation over the Indian and west Pacific Oceans, J. Geophy. Sci., 118, 6996-7023. 
970

971

972

973

974

975

976

977

978

979

980

981

982

983

984

985

986

987

988

989

990

991

992

993

994

995

996

997

998

999

1000

1001

1002

1003

1004

1005

1006

1007

1008

1009

1010

1011

1012

1013

1014

1015

1016

Ciesielski, P. E., H. Yu, R. H. Johnson, K. Yoneyama, C. N. Long, J. Wang, S. M. Loehrer, K. Youngg, S. F. Williams (2014), Quality-controlled upper-air sounding dataset for DYNAMO/CINDY/AMIE: Development and corrections, J. Atmos. Ocean. Tech., 31, 741-764.

Depasquale, A., C. Schumachr, and A. Rapp (2014), Radar observations of MJO and Kelvin wave interactions during DYNAMO/CINDY2011/AMIE, J. Geophy. Res., 119, 6347-6367, doi:10.1002/2013JD021031.

Fridlind, A. M., A. S. Ackerman, J.-P. Chaboureau, et al. (2012), A comparison of TWPICE observational data with cloud-resolving model results, J. Geophy. Res., 117, D05204, doi:10.1029/2011JD016595.

Grabowski, W. W., and H. Morrison (2008) Toward the mitigation of spurious cloudedge supersaturation in cloud models. Mon. Wea.Rev., 136, 1224-1234, doi:https://doi.org/10.1175/2007MWR2283.1.

Hagos, S., Z. Feng, C. D. Burleyson, K.-S. Lim, C. N. Long, D. Wu, and G. Thompson (2014a), Evaluation of convection-permitting model simulations of cloud populations associated with the Madden-Julian Oscilattion using data collected during the AMIE/DYNAMO field campaign, J. Geophy. Res. Atmos., 119, 12,05212,068, doi:10.1002/2014JD022143.

Hagos, S., Z. Feng, K. Landu, and C. N. Long (2014b), Advection, moistening, and shallow-to-deep convection transitions during the initiation and propagation of Madden-Julian Oscillation, J. Adv. Model Earth Sys., 6, 938-949, doi:10.1002/2014MS000335.

Houze, R. A. (2004), Mesoscale convective systems, Rev. Geophys., 42, RG4003, doi:10.1029/2004RG000150.

Huffman, G. J., D. T. Bovin, E. J. Nelkin, D. B. Wolff, R. F. Adler, G. Gu, Y. Hong, K. P. Bowman, E. F. Stocker (2007), The TRMM multisatellite precipitation analysis (TMPA): Quasi-global, multiyear, combined-sensor precipitation estimates at fine scales, J. Hydrometeor., 8, 38-55.

Janiga, M. A., and C. Zhang (2016), MJO moisture budget during DYNAMO in a cloudresolving model, J. Atmos. Sci., 73, 2257-2278.

Johnson, R. H., and P. E. Ciesielski (2013), Structure and properties of Madden--Julian Oscillations deduced from DYNAMO sounding arrays, J. Atmos. Sci., 70, 31573179.

Johnson, R. H., P. E. Ciesielski, J. H. Ruppert Jr., and M. Katsumata (2015), Soundingbased thermodynamic budgets for DYNAMO, J. Atmos. Sci., 72, 598-622.

Khairoutdinov, M. F., and D. A. Randall (2003), Cloud resolving modeling of the ARM summer 1997 IOP: Model formulation, results, uncertainties, and sensitivities, $J$. Atmos. Sci., 60, 607-625.

Klaassen, G. P., and T. L. Clark (1985), Dynamics of the cloud-environment interface and entrainment in small cumuli: Two-dimensional simulations in the absence of ambient shear, J. Atmos. Sci., 42, 2621-2641.

Lang, S., W.-K. Tao, R. Cifelli, W. Olson, J. Halverson, S. Rutledge, and J. Simpson (2007), Improving simulations of convective systems from TRMM LBA: Easterly and westerly regimes, J. Atmos. Sci., 64, 1141-1164.

Lang, S., W.-K. Tao, J.-D. Chern, D. Wu, X. Li (2014), Benefits of a 4th ice class in the simulated radar reflectivities of convective systems using a bulk microphysics scheme, $J$. Atmos. Sci., 713583-3612, doi:/http://dx.doi.org/10.1175/JAS. 
1017

1018

1019

1020

1021

1022

1023

1024

1025

1026

1027

1028

1029

1030

1031

1032

1033

1034

1035

1036

1037

1038

1039

1040

1041

1042

1043

1044

1045

1046

1047

1048

1049

1050

1051

1052

1053

1054

1055

1056

1057

1058

1059

1060

1061

1062

LeMone, M. A., E. J. Zipser, and S. B. Trier (1998), The role of environmental shear and thermodynamic conditions in determining the structure and evolution of mesoscale convective systems during TOGA COARE, J. Atmos. Sci., 55, 3493-3518.

Liu, C., E. J. Zipser, D. J. Cecil, S. W. Nesbitt, and S. Sherwood (2008), A cloud and precipitation feature database from 9 years of TRMM observations, J. Appl. Meteor., 47, 2712-2728 doi:10.1175/2008JAMC1890.1.

Matsui, T., X. Zeng, W.-K. Tao, H. Masunaga, W. Olson, and S. Lang (2009), Evaluation of long-term cloud-resolving model simulations using satellite radiance observations and multi-frequency satellite simulators, J. Atmos. Ocean. Tech., 26, 1261-1274.

Matsui, T. et al. (2013), GPM satellite simulator over ground validation sites, Bull. Amer. Meteor. Soc., 94, 1653-1660, doi: http://dx.doi.org/10.1175/BAMS.

Morrison, H., J. A. Curry, and V. I. Khvorostyanov (2005), A new double-moment microphysics parameterization for application in cloud and climate models. Part I: Description, J. Atmos. Sci., 62, 1665-1677.

Powell, S. W., and R. A. Houze Jr. (2015), Evolution of precipitatoin and convective echo top heights observed by TRMM radar over the Indian Ocean during DYNAMO, J. Geophy. Res. Atmos., 120, 3906-3919, doi:10.1002/2014JD022934.

Rowe, A. K., and R. A. Houze Jr. (2014), Microphysical characteristics of MJO convection over the Indian Ocean during DYNAMO, J. Geophy. Res., 119, 25432554, doi:10.1002/2013JD020799.

Rowe, A. K., and R. A. Houze, Jr. (2015), Cloud organization and growth during the transition from suppressed to active MJO conditions. J. Geophys. Res. Atmos., 120, 10,324-10,350, doi:10.1002/2014JD022948.

Ruppert Jr, J. H., and R. H. Johnson (2015), Diurnally modulated cumulus moistening in the preonset stage of the Madden-Julian Oscillation during DYNAMO, J. Atmos. Sci., 72, 1622-1647.

Skamarock, W. C., J. B. Klemp, J. Dudhia, D. O. Gill, D. M. Barker, M. G. Duda, X. Huang, W. Wang, and J. G. Powers (2008), A description of the Advanced Research WRF version 3, NCAR Tech. Note NCAR/TN-475+STR, 125 pp.

Steiner, M., R. A. Houze Jr., and S. E. Yuter (1995), Climatological characterization of three-dimensional storm structure from operational radar and rain gauge data, $J$. Appl. Meteor., 34, 1978-2007.

Tao, W.-K. et al. (2009), A Goddard multi-scale modeling system with unified physics, Annales Geophysicae, 27, 3055-3064.

Tao, W.-K. et al. (2014), The goddard cumulus ensemble (gce) model: Improvements and applications for studying precipitation processes., Atmos. Res., 143, 392-424.

Varble, A., A. M. Fridlind, E. J. Zipser, A. S. Ackerman, J. P. Chaboureau, J. Fan, A. Hill, S. A. McFarlane, J. P. Pinty, and B. Shipway (2011), Evaluation of cloud-resolving model intercomparison simulations using TWP-ICE observations: Precipitation and cloud structure, J. Geophys. Res., 116, D12206, doi:10.1029/2010JD015180.

Varble, A., E. J. Zipser, A. M. Fridlind, P. Zhu, A. S. Ackerman, J. P. Chaboureau, S. Collis, J. Fan, A. Hill, and B. Shipway (2014), Evaluation of cloud-resolving and limited area model intercomparison simulations using TWP-ICE observations. Part I: Deep convective updraft properties, J. Geophy. Res., 119, 13,89113,918,doi:10.1002/2013JD021371. 
1063

1064

1065

1066

1067

1068

1069

1070

1071

1072

1073

1074

1075

1076

1077

1078

1079

1080

1081

1082

1083

1084

1085

1086

1087

1088

1089

1090

1091

1092

1093

1094

1095

1096

1097

1098

1099

1100

1101

1102

1103

1104

1105

1106

1107

1108

Wang, S., and A. H. Sobel (2011), Response of convection to relative sea surface temperature: Cloud resolving simulations in two and three dimensions, J. Geophys. Res., 116, D11119.

Wang, S., A. H. Sobel, and Z. Kuang (2013), Cloud-resolving simulation of TOGACOARE using parameterized large-scale dynamics. J. Geophys. Res., 118, doi:10.1002/jgrd.50510.

Wang, S., A. H. Sobel, F. Zhang, Y. Q. Sun, Y. Yue, and L. Zhou (2015a), Regional simulation of the october and november mjo events observed during the CINDY/DYNAMO field campaign at gray zone resolution, J. Clim., 28, 2097-2119.

Wang, S., A. H. Sobel, A. Fridlind, Z. Feng, J. M. Comstock, P. Minnis, and M. L. Nordeen (2015b), Simulations of cloud-radiation interaction using large-scale forcing derived from the CINDY/DYNAMO northern sounding array, $J$. Adv. Model Earth Sys., 7, 1472-1498, doi:10.1002/2015MS000461.

Wang, S., A. H. Sobel, and J. Nie (2016), Modeling the mjo rain rates using parameterized large scale dynamics: Vertical structure, radiation, and horizontal advection of dry air, J. Adv. Model. Earth Syst., 8, 121-139, doi:10.1002/2015MS000529.

Wu, J., A. D. Del Genio, M.-S. Yao, and A. B. Wolf (2009), WRF and GISS SCM simulations of convective updraft properties during TWP-ICE, J. Geophy. Res., 114, D04206, doi:10.1029/2008JD010851.

Xie, S., T. Hume, C. Jakob, S. Klein, R. B. Mccoy, and M. Zhang (2010), Observed large-scale structures and diabatic heating and drying profiles during TWP-ICE, $J$. Clim, 23, 57-79.

$\mathrm{Xu}, \mathrm{W}$. , and S. A. Rutledge (2015), Morphology, intensity and rainfall production of MJO convection: Observations from DYNAMO shipborned radar and TRMM, $J$. Atmos. Sci., 72, 623-640.

Xu, W., and S. A. Rutledge (2014), Convective charactristics of the Madden-Julian Oscillation over the centeral Indian Ocean observed by shipborne radar during DYNAMO, J.Atmos. Sci., 71, 2859-2877.

Xu, W., S. A. Rutledge, C. Shumacher, and M. Katsumata (2015), Evolution, properties, and spatial variability of MJO convection near and off the equator during DYNAMO, J. Atmos. Sci., 72, 4126-4147.

Yoneyama, K., C. Zhang, and C. N. Long (2013), Tracking pulses of the Madden-Julian Oscillation, Bull. Amer. Meteor. Soc., 94, 1871-1891.

Yuter, S. E., and R. A. H. Jr. (1995), Three-dimensional kinematic and microphysical evolution of Florida cumulonimbus. Part II: Frequency distributions of vertical velocity, reflectivity, and differential reflectivity., Mon. Wea.Rev., 123, 1941-1963.

Zhang, M. H., and J. L. Lin (1997), Constrained variational analysis of sounding data based on column-integrated budgets of mass, heat, moisture, and momentum: Approach and application to arm measurements, J. Atmos. Sci., 54, 1503-1524.

Zhang, M. H., J. L. Lin, R. T. Cederwall, J. J. Yio, and S. C. Xie (2001), Objective analysis of ARM IOP data: Method and sensitivity, Mon. Wea. Rev., 129, 295-311.

Zuluaga, M. D., and R. A. Houze, Jr. (2013), Evolution of the population of precipitating convective systems over the Equatorial Indian Ocean in Active Phases of the Madden-Julian Oscillation. J. Atmos Sci., 70, 2713-2725. 
1109

1110

1111

1112

1113

1114

1115

1116

1117

1118 
Table 1: Summary of CRM simulations' setup and model parameters.

\begin{tabular}{|c|c|c|c|c|c|c|c|c|}
\hline Model & Equations & Microphysics & Radiation & Surface Fluxes & $\begin{array}{l}\text { Subgrid } \\
\text { mixing }\end{array}$ & Forcing & Domain $(\mathrm{km})$ & $\begin{array}{c}\Delta \mathrm{x}, \Delta \mathrm{y}, \Delta \mathrm{z} \\
(\mathrm{km})\end{array}$ \\
\hline SAM & anelastic & Morrison & RRTM & $\begin{array}{c}\text { Calculated } \\
\text { w/SST }\end{array}$ & Smagorinsky & NSA & $256 \times 256 \times 30$ & $1,1,0.25$ \\
\hline WRF & compressible & Morrison & $\begin{array}{c}\text { RRTMG } \\
\text { (shortwave) } \\
\text { Goddard } \\
\text { (longwave) }\end{array}$ & $\begin{array}{l}\text { Calculated } \\
\text { w/SST }\end{array}$ & Smagorinsky & NSA & $256 \times 256 \times 30$ & $1,1,0.25$ \\
\hline \multirow{3}{*}{ GCE } & \multirow{3}{*}{ anelastic } & \multirow{3}{*}{$\begin{array}{l}\text { Morrison } \\
\text { or } \\
\text { Goddard } \\
\text { 3ICE }\end{array}$} & \multirow{3}{*}{ Goddard } & \multirow{3}{*}{$\begin{array}{c}\text { Prescribed } \\
\text { w/ observation }\end{array}$} & \multirow{3}{*}{$\begin{array}{c}\text { Prognostic } \\
\text { TKE }\end{array}$} & $\mathrm{NSA}$ & \multirow{3}{*}{$\begin{array}{c}256 \times 256 \times 30 \\
\text { or } \\
1024 \times 1024 \times 30\end{array}$} & \multirow{3}{*}{$\begin{array}{c}1,1,0.25 \\
\text { or } \\
1,1,0.5\end{array}$} \\
\hline & & & & & & Addu & & \\
\hline & & & & & & Revelle & & \\
\hline
\end{tabular}




\section{Figure Captions:}

Fig. 1: Schematic plot of DYNAMO sounding array and radar locations. The sounding observations from Malé, Columbo, Gan Island of Addu Atoll, and R/V Revelle are used to derive the NSA large-scale forcing. The yellow circles indicate sounding frequency of 4 times daily; red circles of 8 times daily. Radars were deployed on Addu Atoll, R/V Revelle and R/V Mirai. Adapted from Ciesielski et al. [2014].

Fig. 2: Surface rainfall observed (black lines) and simulated (colored lines) during the November MJO event for (a) the Addu forcing simulation, (b) Revelle forcing simulation, and (c) NSA forcing simulation.

Fig. 3: Comparisons of the 0-dBZ radar echo-top height distributions observed by SPolKa radar (3a) and C-band radar (3c), and simulated by the GCE model using Addu forcing at the S-PolKa site (3b) and Revelle forcing at the C-band radar site (3d). The color images are frequencies of the 0 -dBZ height occurrences. The black lines represent the median of the $0-\mathrm{dBZ}$ echo-top heights with a 24 -hour running mean.

Fig. 4: Comparisons of the convective/stratiform separation snapshots between S-PolKa observed (upper row) and GCE simulated (lower row) scenes at different MJO phases. Red represents convective area and green presents stratiform. The three columns illustrate transitions from isolated convection (left column at 00 UTC on Nov. 18) to organized convection (middle column at 14 UTC on Nov. 23) to deep stratiform clouds (right column at 00 UTC on Nov. 24) during the passage of the November MJO event at the Addu site.

Fig. 5: Time series of convective vs. stratiform rainfall rate observed by S-PolKa radar (5a) and C-band radar (5c), and simulated by GCE with Addu forcing (5b) and Revelle forcing $(5 \mathrm{~d})$. The black lines are the convective rain rates; the red lines are the stratiform rain rates.

Fig. 6: Time series of the convective feature size frequency distributions (color shaded) observed by S-PolKa radar (6a) and C-band radar (6c), and simulated by the GCE using the Addu forcing (6b) and Revelle forcing (6d). Red lines represent the total numbers of features within the observation/simulation domain; black lines represent the mean sizes of the convective features, both of which are 24-hour running means.

Fig. 7: Contour plots of probability density function of the 17-dBZ feature length vs. the maximum 0 -dBZ echo-top height for every individual precipitation feature. Fig. 7a is the $\mathrm{S}-\mathrm{PolKa}$ radar observation. Fig. $7 \mathrm{~b}$ is the GCE simulation using the Addu large-scale forcing. Fig. 7c is the C-band radar observation, and Fig. 7d is the GCE simulation using Revelle forcing. Both S-PolKa and C-band use only data within $100 \mathrm{~km}$ range.

Fig. 8: Comparisons of the 17-dBZ radar echo-top height distributions observed by the TRMM PR radar (8a) and simulated by the GCE model using NSA forcing (8b). The 
color images are frequencies of the $17 \mathrm{dBZ}$ height occurrences. The black lines represent the median echo-top heights with a 24-hour running mean.

Fig. 9: Comparisons of precipitation feature size distributions, defined by the 17-dBZ near surface radar reflectivity. The black line is the TRMM PR observation between November 1 and December 1, 2011, within the NSA. The red line is the GCE model simulated feature size distribution over the same period.

Fig. 10: Contours of probability density function of the 17-dBZ precipitation features' effective lengths vs. the maximum 17-dBZ echo-top heights. Fig. 10a is the TRMM PR observation over the NSA in November 2011. Fig. 7b is the GCE simulation using NSA forcing over the same period.

Fig. 11: The same as Fig. 3, except for CRM simulations using the NSA forcing for the month of November 2011. Fig. 11a is the GCE simulation using the Goddard 3ICE microphysical scheme; $11 \mathrm{~b}$ is the GCE simulation using the Morrison two-moment scheme; 11c is SAM and 11d is WRF simulation, both using the Morrison two-moment scheme. The dark lines represent the median cloud-top heights with a 24-hour running mean.

Fig. 12: Same as Fig. 6, except for different CRM simulations. Fig. 12a is the GCE model with the 3ICE microphysical scheme; 12b is the GCE model with the Morrison two-moment microphysical scheme; 12c is the SAM model, also with Morrison scheme; $12 \mathrm{~d}$ is the WRF model with Morrison scheme.

Fig. 13: The same as Fig. 11, except for GCE model with Goddard 3ICE scheme, using coarser vertical resolutions of 45 vertical levels instead of 106 as shown in Fig. 11. Fig. $13 \mathrm{a}$ is the small-domain simulation using $256 \mathrm{~km} \times 256 \mathrm{~km}$ horizontal domain with $1 \mathrm{~km}$ resolution, as in all previous simulations. Fig. 13b uses $1024 \mathrm{~km}$ x $1024 \mathrm{~km}$ horizontal domain with 1-km resolution. Fig. 13c is the same as Fig. 13a, except for reducing graupel sizes in the Goddard microphysical scheme. Fig. 13d is the same as Fig. 13a, except for removing cloud evaporation and ice sublimation where vertical air velocities are higher than $0.5 \mathrm{~m} / \mathrm{s}$. Fig. 13e is the same as Fig. 13a, except for raising the upper boundary sponge layer $3 \mathrm{~km}$ higher. The dark lines again represent the median cloud top heights with a 24-hour running mean.

Fig. 14: Scatter plots of the precipitation feature effective sizes vs. the maximum 17-dBZ echo-top heights, showing feature sizes up to $400 \mathrm{~km}$ for large-domain simulation comparisons. Fig. $14 \mathrm{a}$ and $14 \mathrm{c}$ are the small-domain simulations using the $256 \times 256 \mathrm{~km}$ domain size. Fig. 14a has 45 vertical levels and Fig. 14c has 106 vertical levels. Fig. 14b is the large-domain simulation with $1024 \times 1024 \mathrm{~km}$ domain size and 45 vertical levels. Fig. 14d is the TRMM observation. Fig. 14d (14c) is the same as Fig. 10a (10b) except for an extended $\mathrm{x}$-axis range.

Fig. 15: Summary of the radar echo-top height variations during the DYNAMO November MJO event, using various observations and simulations. The $\mathrm{x}$-axis is the correlation coefficients of the median echo-top height time series (the black lines in 
previous figures); the $y$-axis is their mean differences. Circles represent model-model comparisons; triangles are radar-radar comparisons; squares are model-radar comparisons. Each label indicates the single parameter that differs in the comparison pair, where the first label always has a higher echo-top height. In observations, range 1 represents subsampling of the original data range $(0 \mathrm{~km}$ to $150 \mathrm{~km})$, between $20 \mathrm{~km}$ and $120 \mathrm{~km}$; range 2 is from $20 \mathrm{~km}$ to $100 \mathrm{~km}$. 


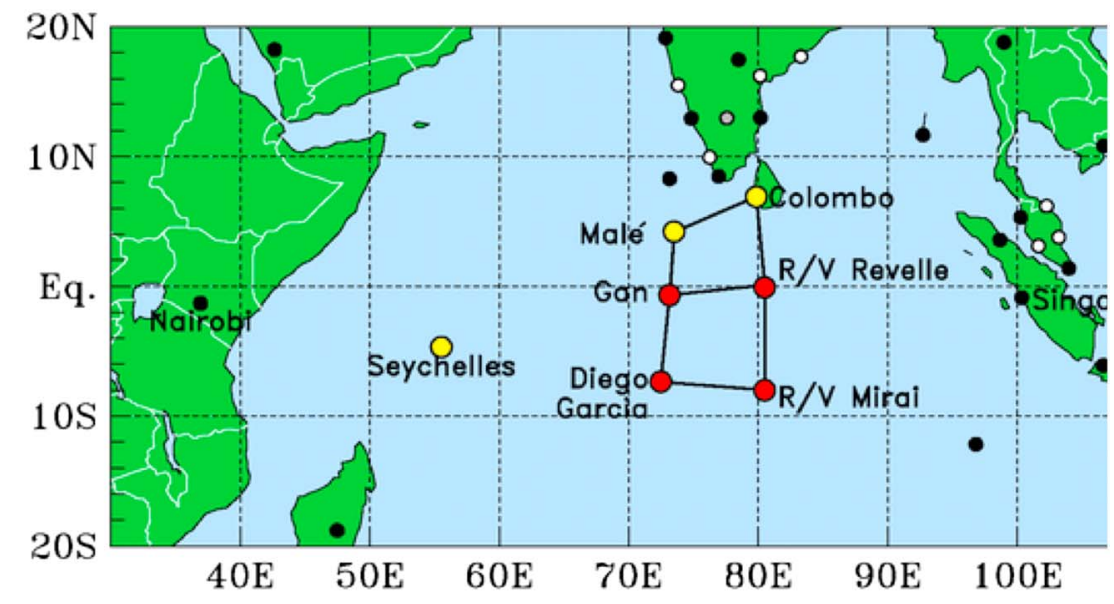

Figure 1. Schematic plot of DYNAmics of the Madden-Julian Oscillation sounding array and radar locations. The sounding observations from Malé, Columbo, Gan Island of Addu Atoll, and R/V Revelle are used to derive the NSA large-scale forcing. The yellow circles indicate sounding frequency of 4 times daily; red circles of 8 times daily. Radars were deployed on Addu Atoll, R/V Revelle, and R/V Mirai. Adapted from Ciesielski et al. (2014). 

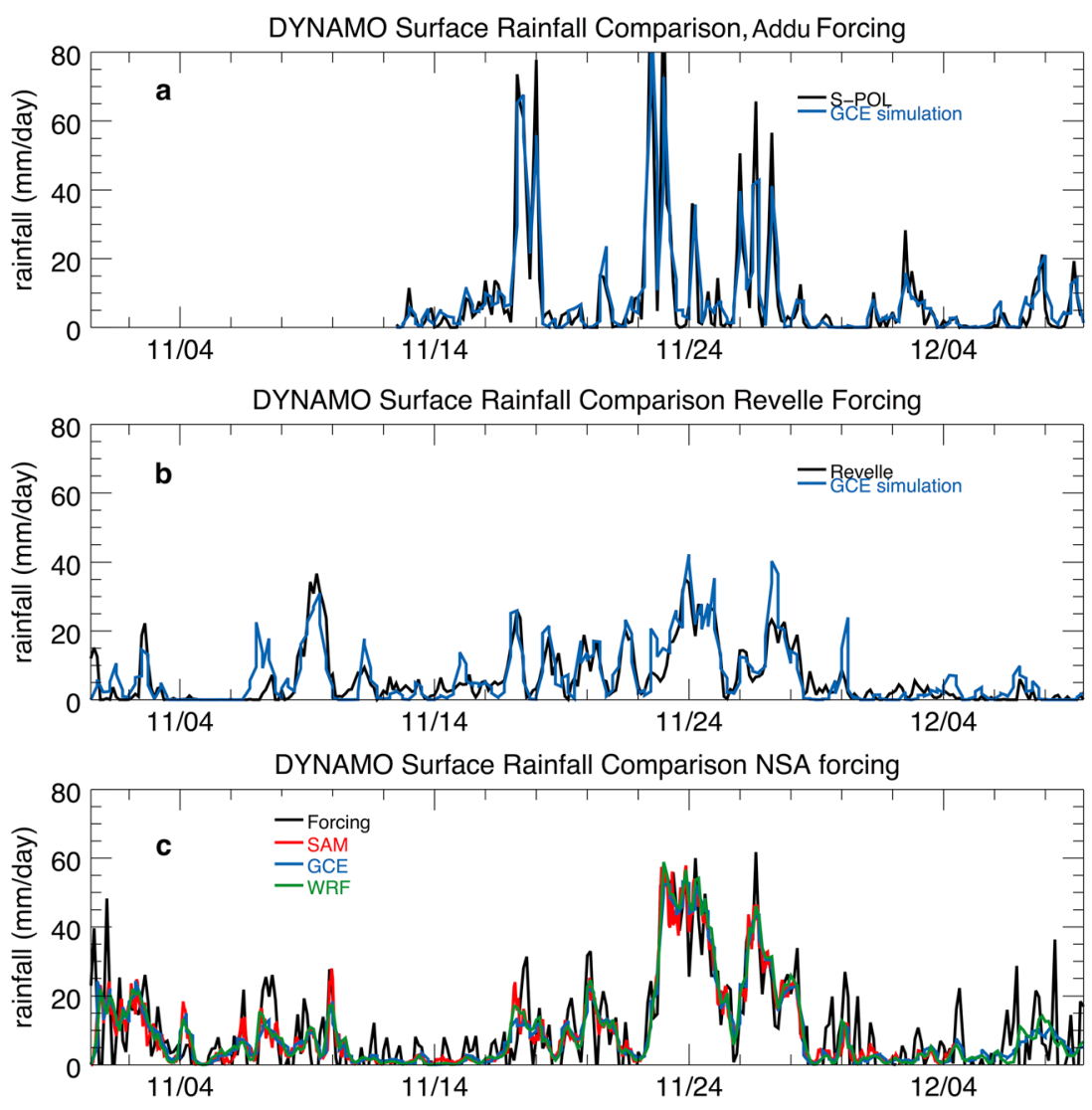

Figure 2. Surface rainfall observed (black lines) and simulated (colored lines) during the November Madden-Julian Oscillation event for (a) the Addu forcing simulation, (b) Revelle forcing simulation, and (c) northern sounding array (NSA) forcing simulation. DYNAMO: DYNAmics of the Madden-Julian Oscillation; GCE = Goddard Cumulus Ensemble; SAM = System for Atmospheric Modeling; WRF = Weather Research and Forecasting. 

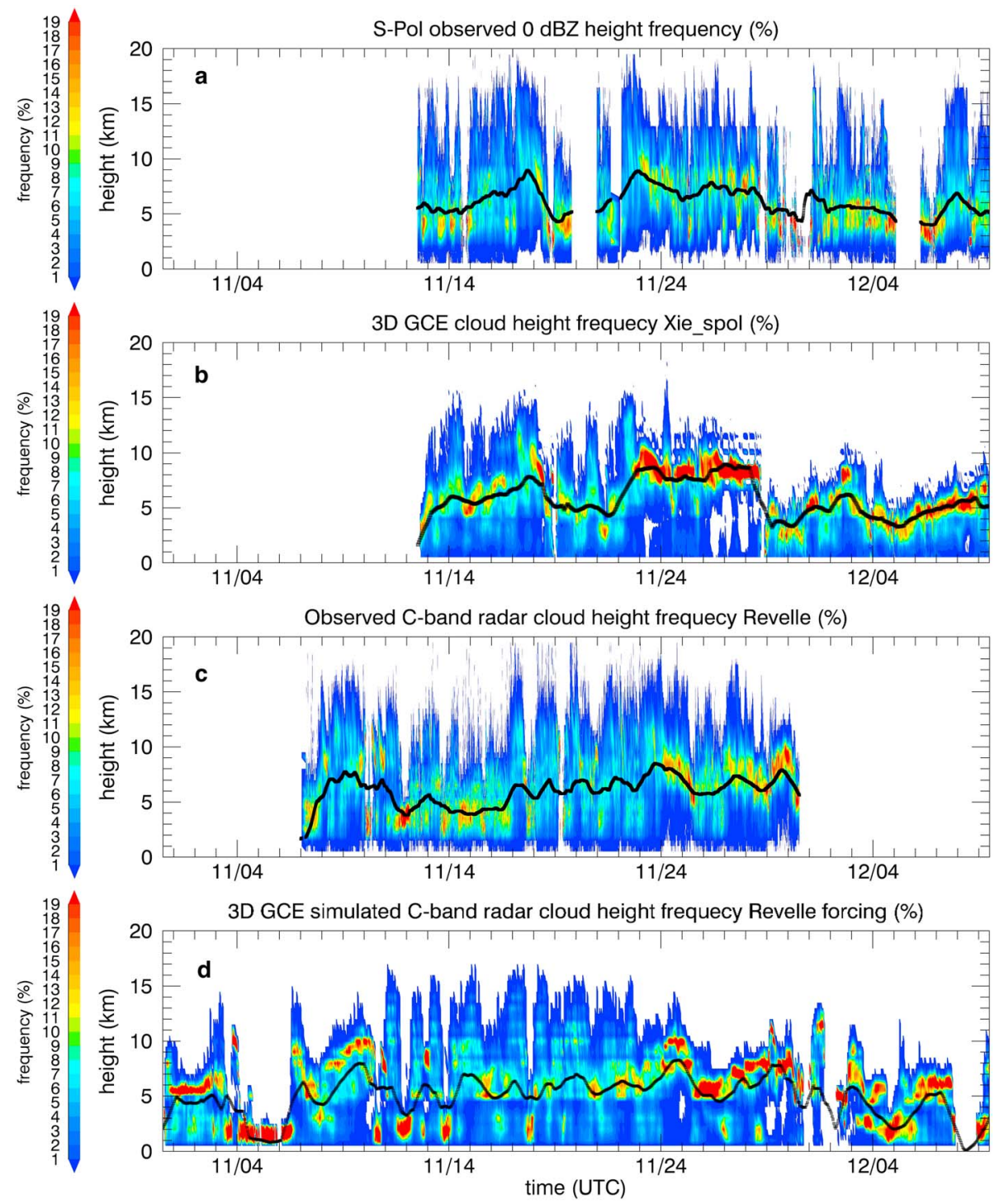

Figure 3. Comparisons of the $0-\mathrm{dBZ}$ radar echo-top height distributions observed by S-PolKa radar (a) and C-band radar (c) and simulated by the GCE model using Addu forcing at the S-PolKa site (b) and Revelle forcing at the C-band radar site (d). The color images are frequencies of the 0-dBZ height occurrences. The black lines represent the median of the $0-\mathrm{dBZ}$ echo-top heights with a 24-hr running mean. GCE $=$ Goddard Cumulus Ensemble. 
Nov. 18, 00:05:00 UTC

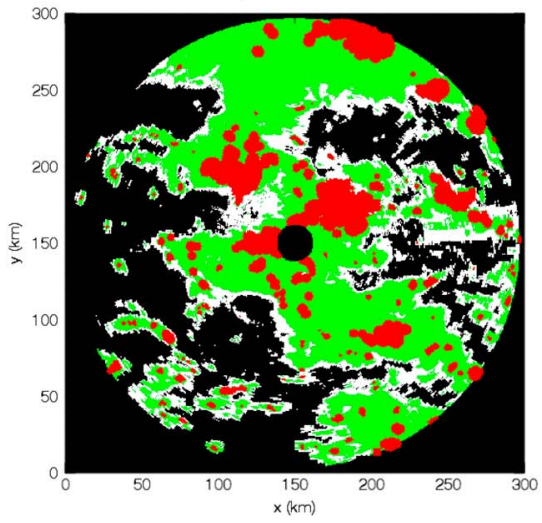

GCE DYNANMO conv strat separation, Nov. 18 @ 00:00

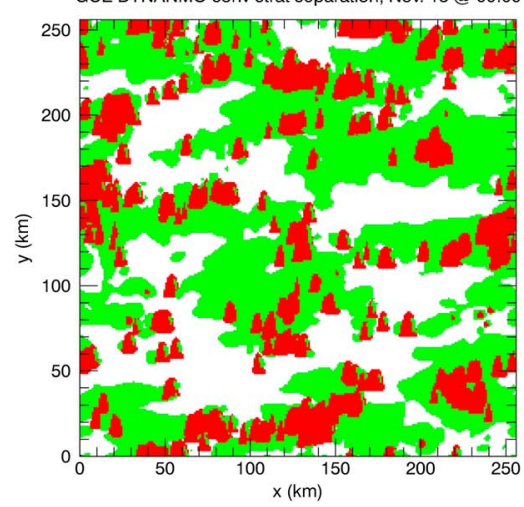

Nov. 23, 14:05:00 UTC

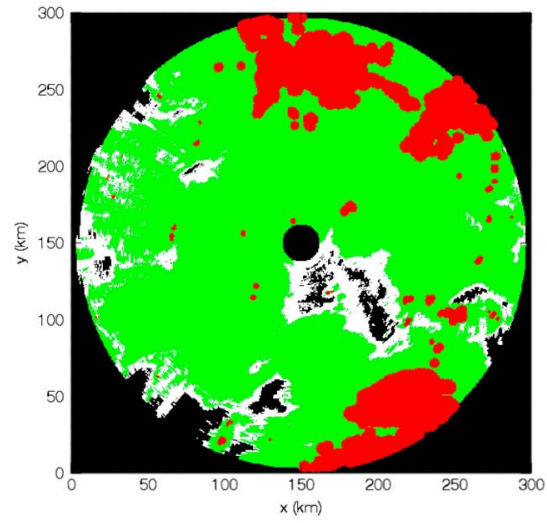

GCE DYNANMO conv strat separation, Nov. 23 @ 14:00

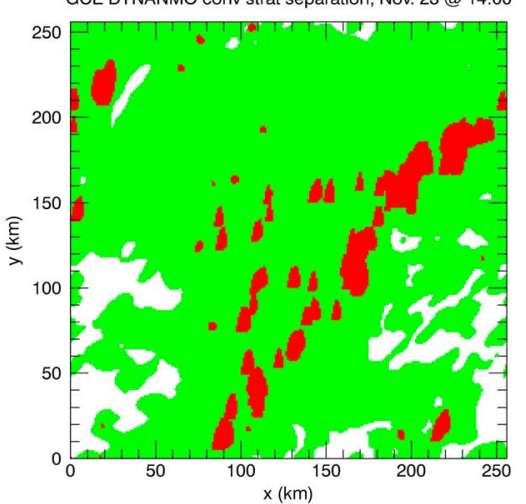

Nov. 24, 00:05:00 UTC

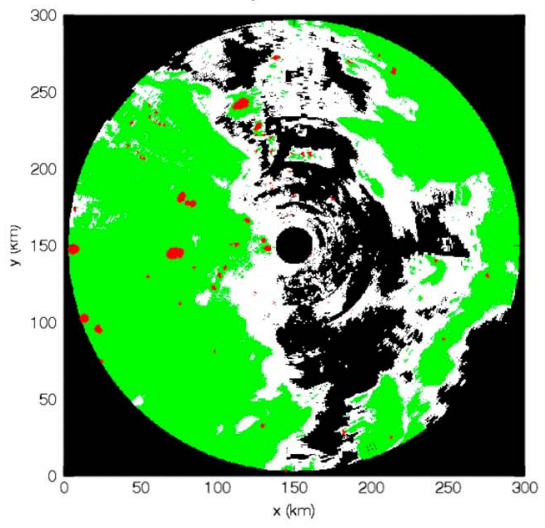

GCE DYNANMO conv strat separation, Nov. 24 @ 00:00

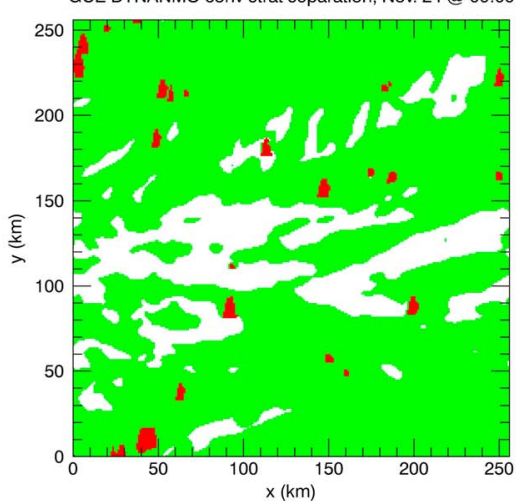

Figure 4. Comparisons of the convective/stratiform separation snapshots between S-PolKa observed (upper row) and GCE simulated (lower row) scenes at different MJO phases. Red represents convective area and green presents stratiform. The three columns illustrate transitions from isolated convection (left column at 00 UTC on 18 November) to organized convection (middle column at 14 UTC on 23 November) to deep stratiform clouds (right column at 00 UTC on 24 November) during the passage of the November Madden-Julian Oscillation event at the Addu site. GCE = Goddard Cumulus Ensemble; DYNAMO: DYNAmics of the Madden-Julian Oscillation. 

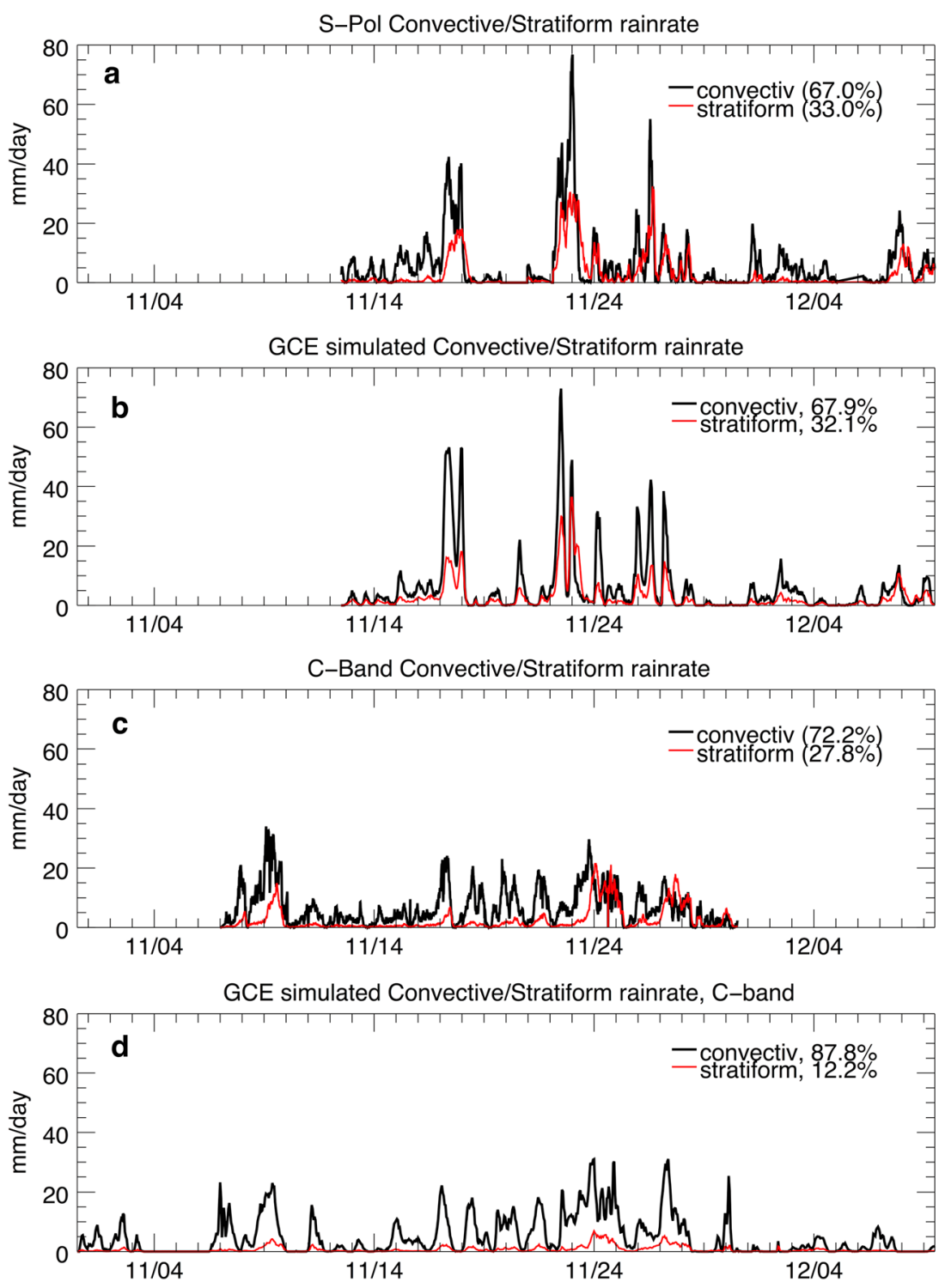

Figure 5. Time series of convective versus stratiform rainfall rate observed by S-PolKa radar (a) and C-band radar (c) and simulated by Goddard Cumulus Ensemble (GCE) with Addu forcing (b) and Revelle forcing (d). The black lines are the convective rain rates; the red lines are the stratiform rain rates. 

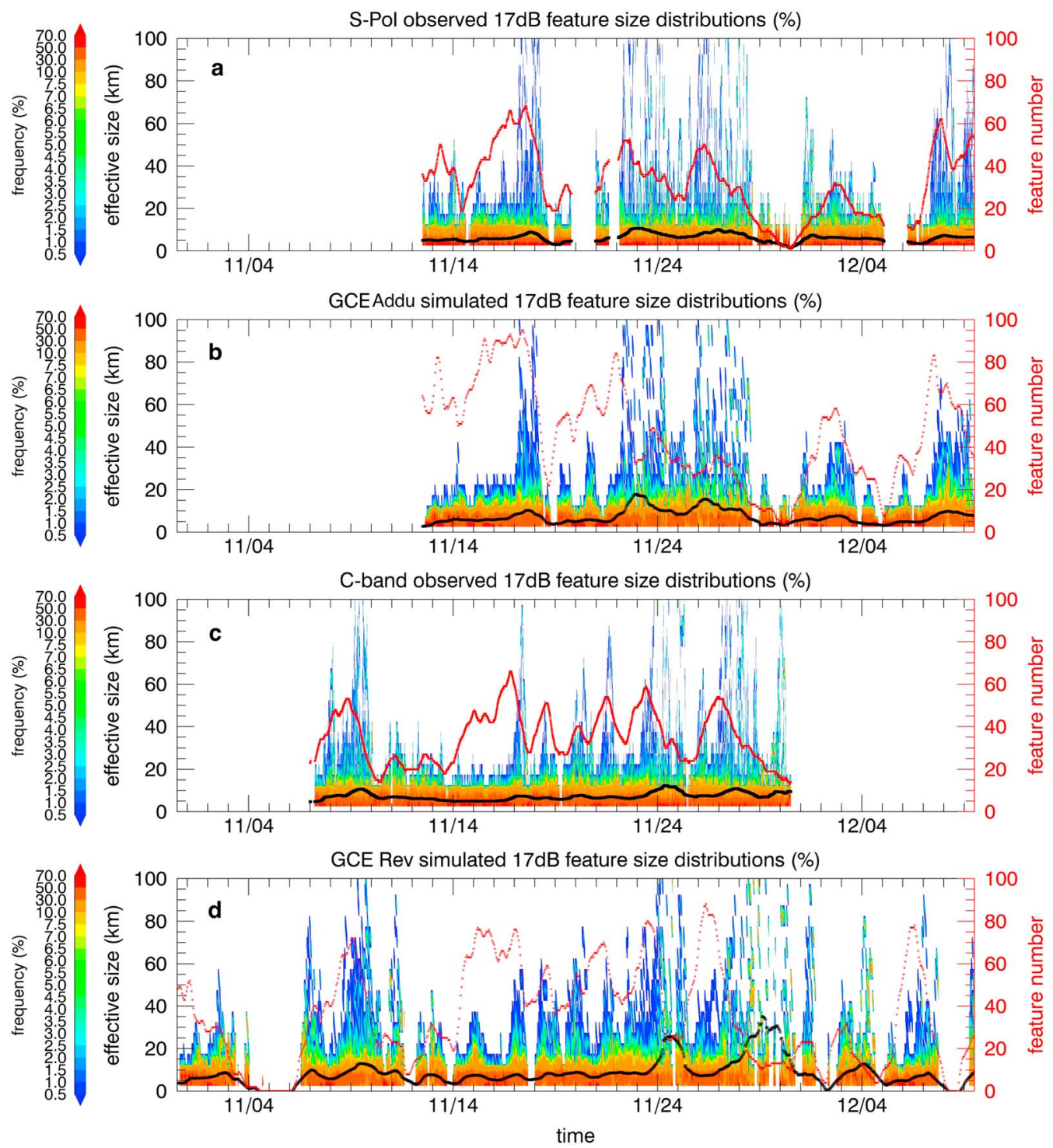

Figure 6. Time series of the convective feature size frequency distributions (color shaded) observed by S-PolKa radar (a) and C-band radar (c) and simulated by the Goddard Cumulus Ensemble (GCE) using the Addu forcing (b) and Revelle forcing (d). Red lines represent the total numbers of features within the observation/ simulation domain; black lines represent the mean sizes of the convective features, both of which are 24-hr running means. 

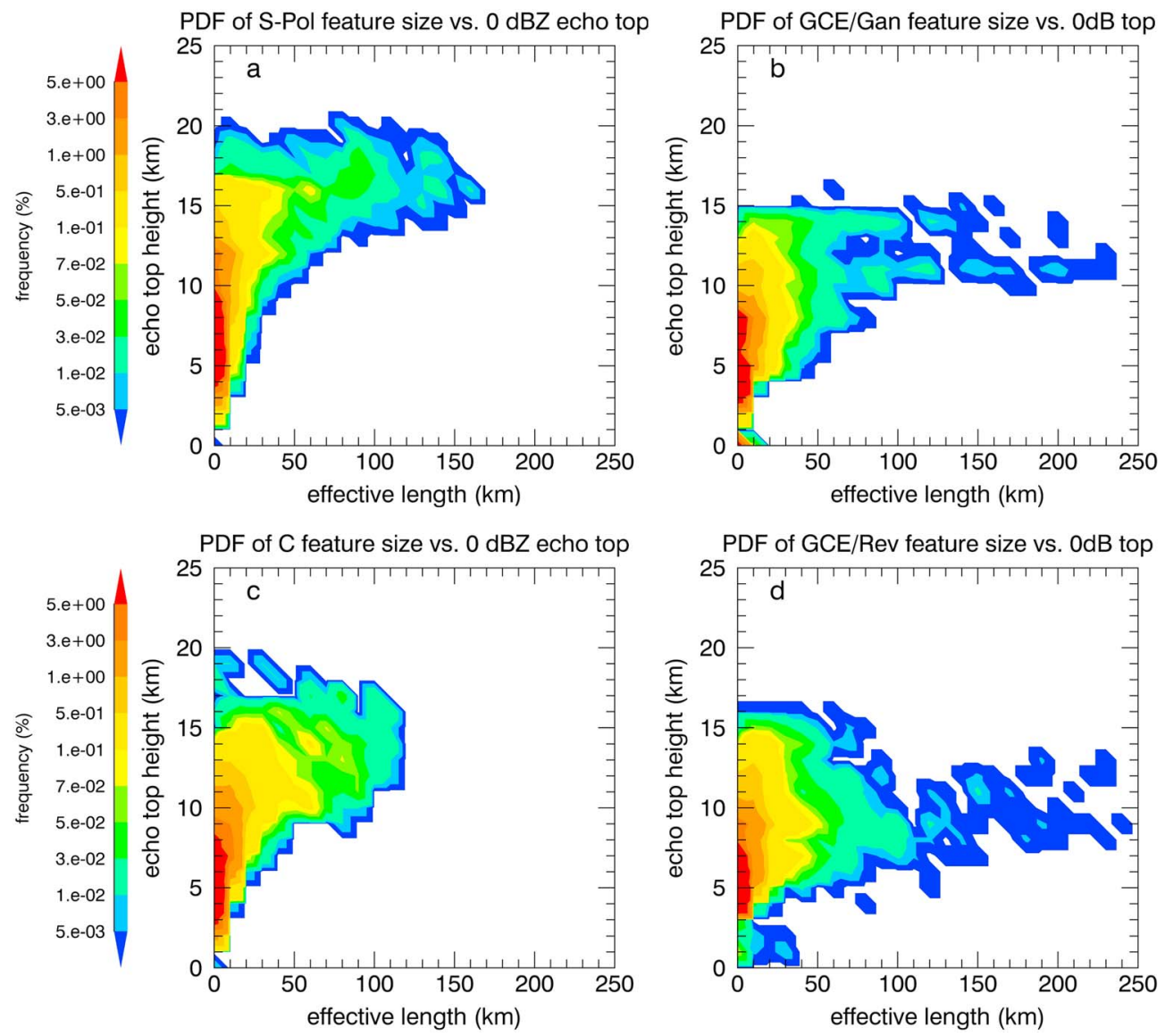

Figure 7. Contour plots of probability density function of the 17-dBZ feature length versus the maximum 0-dBZ echo-top height for every individual precipitation feature. (a) The S-PolKa radar observation. (b) The Goddard Cumulus Ensemble (GCE) model simulation using the Addu large-scale forcing. (c) The C-band radar observation; (d) the GCE simulation using Revelle forcing. Both S-PolKa and C-band use only data within $100 \mathrm{~km}$ range. PR = precipitation radar. 

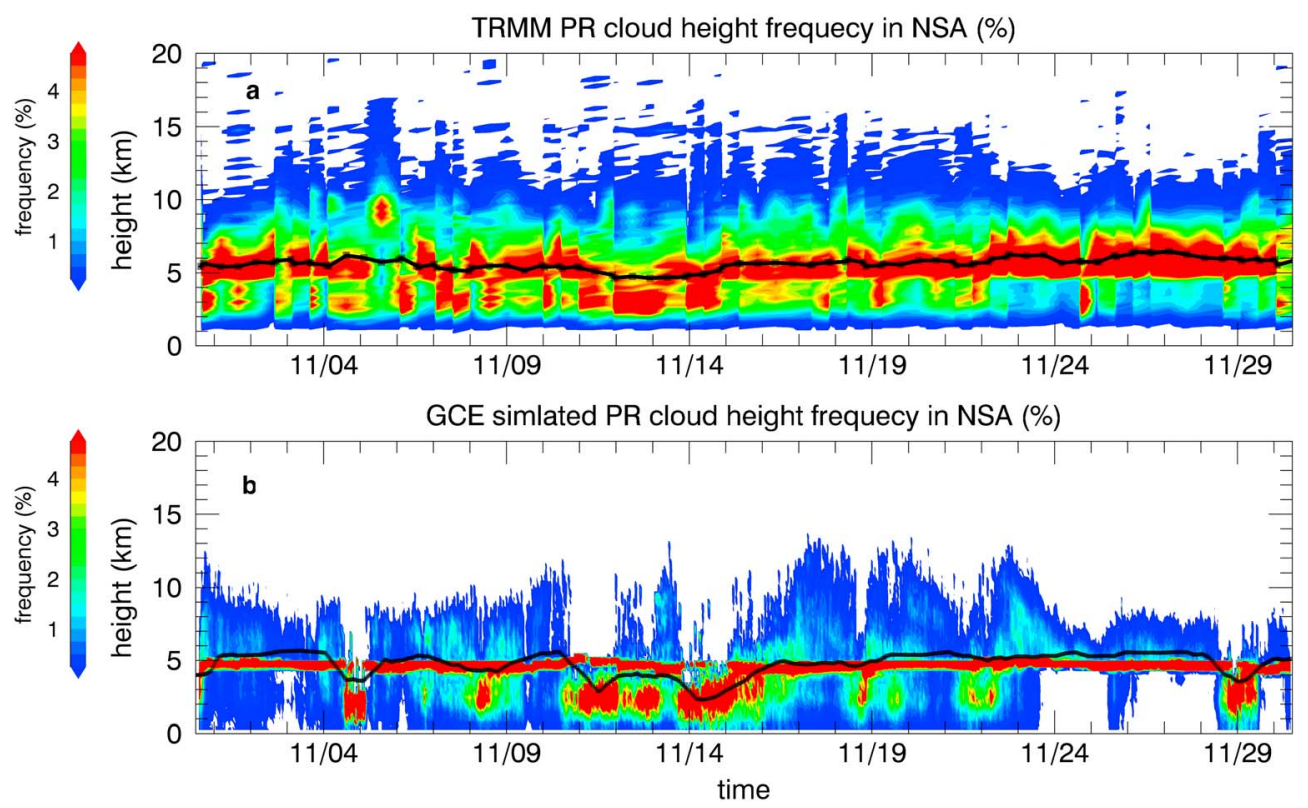

Figure 8. Comparisons of the 17-dBZ radar echo-top height distributions observed by the Tropical Rainfall Measurement Mission precipitation radar (TRMM PR) radar (a) and simulated by the Goddard Cumulus Ensemble (GCE) model using northern sounding array (NSA) forcing (b). The color images are frequencies of the 17-dBZ height occurrences. The black lines represent the median echo-top heights with a 24-hr running mean.

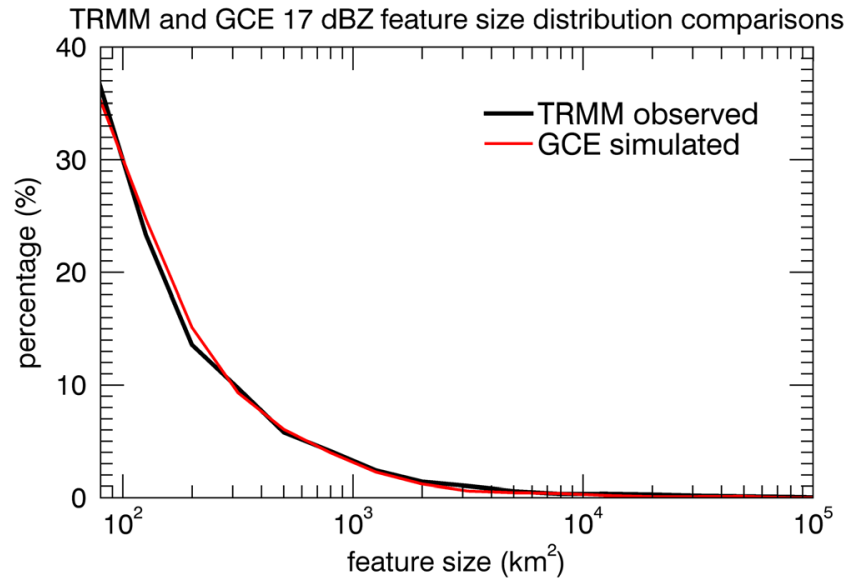

Figure 9. Comparisons of precipitation feature size distributions, defined by the 17-dBZ near surface radar reflectivity. The black line is the Tropical Rainfall Measurement Mission (TRMM) precipitation radar observation between 1 November and 1 December 2011, within the northern sounding array. The red line is the Goddard Cumulus Ensemble (GCE) model simulated feature size distribution over the same period. 

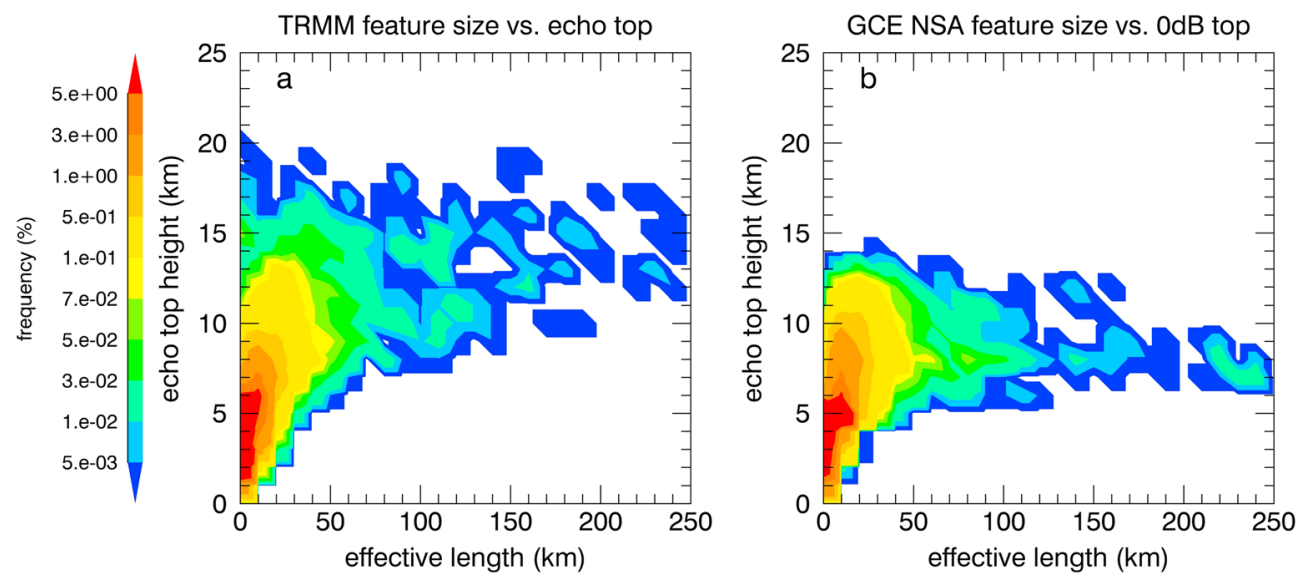

Figure 10. Contours of probability density function of the 17-dBZ precipitation features' effective lengths versus the maximum 17-dBZ echo-top heights. (a) The Tropical Rainfall Measurement Mission (TRMM) precipitation radar observation over the NSA in November 2011. (b) The Goddard Cumulus Ensemble (GCE) simulation using northern sounding array (NSA) forcing over the same period. 

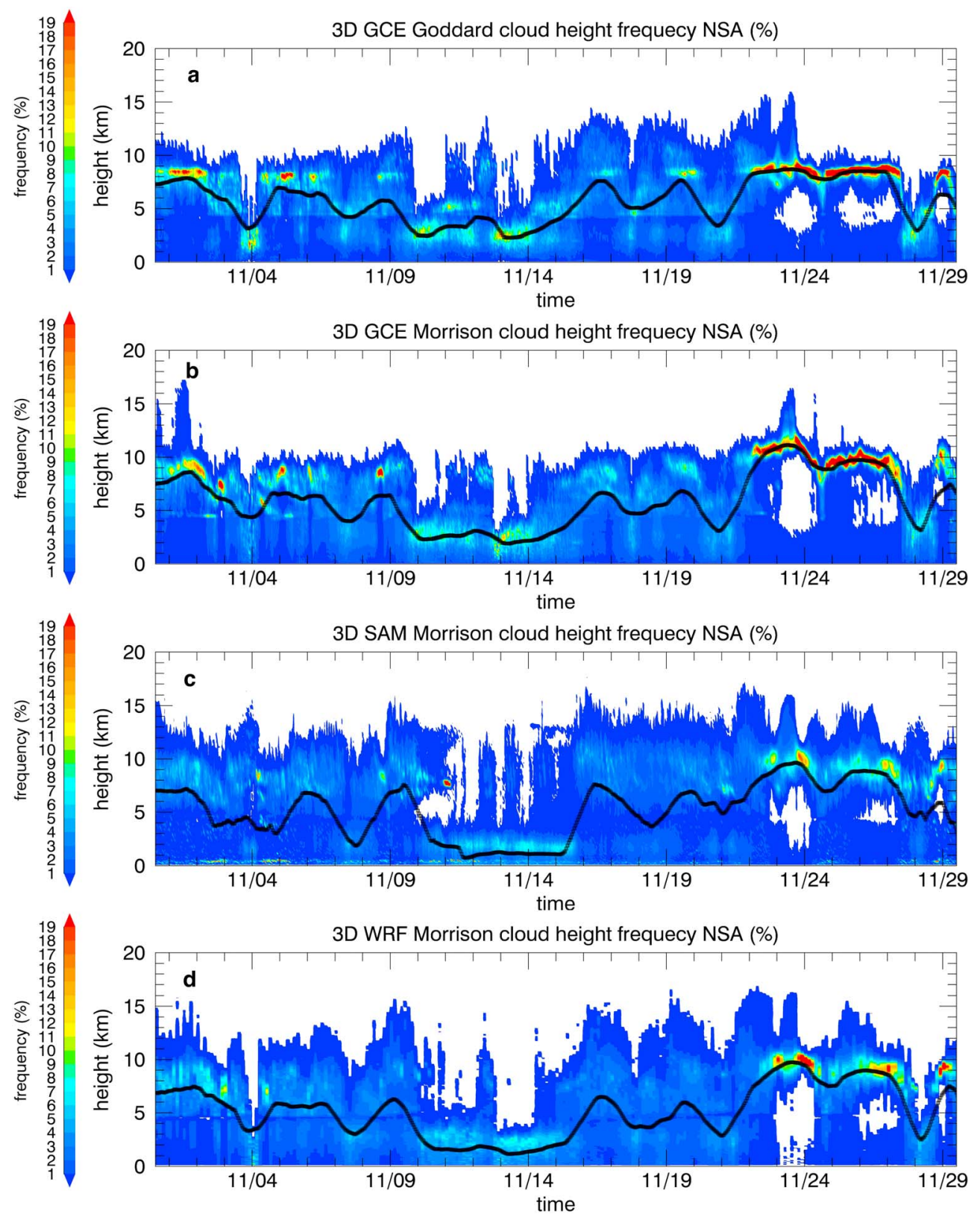

Figure 11. The same as Figure 3 except for cloud-resolving model simulations using the northern sounding array (NSA) forcing for the month of November 2011. (a) The Goddard Cumulus Ensemble (GCE) simulation using the Goddard 3-ICE microphysical scheme; (b) the GCE simulation using the Morrison two-moment scheme; (c) System for Atmospheric Modeling (SAM) and (d) Weather Research and Forecasting (WRF) simulations, both using the Morrison two-moment scheme. The dark lines represent the median cloud top heights with a 24-hr running mean. 

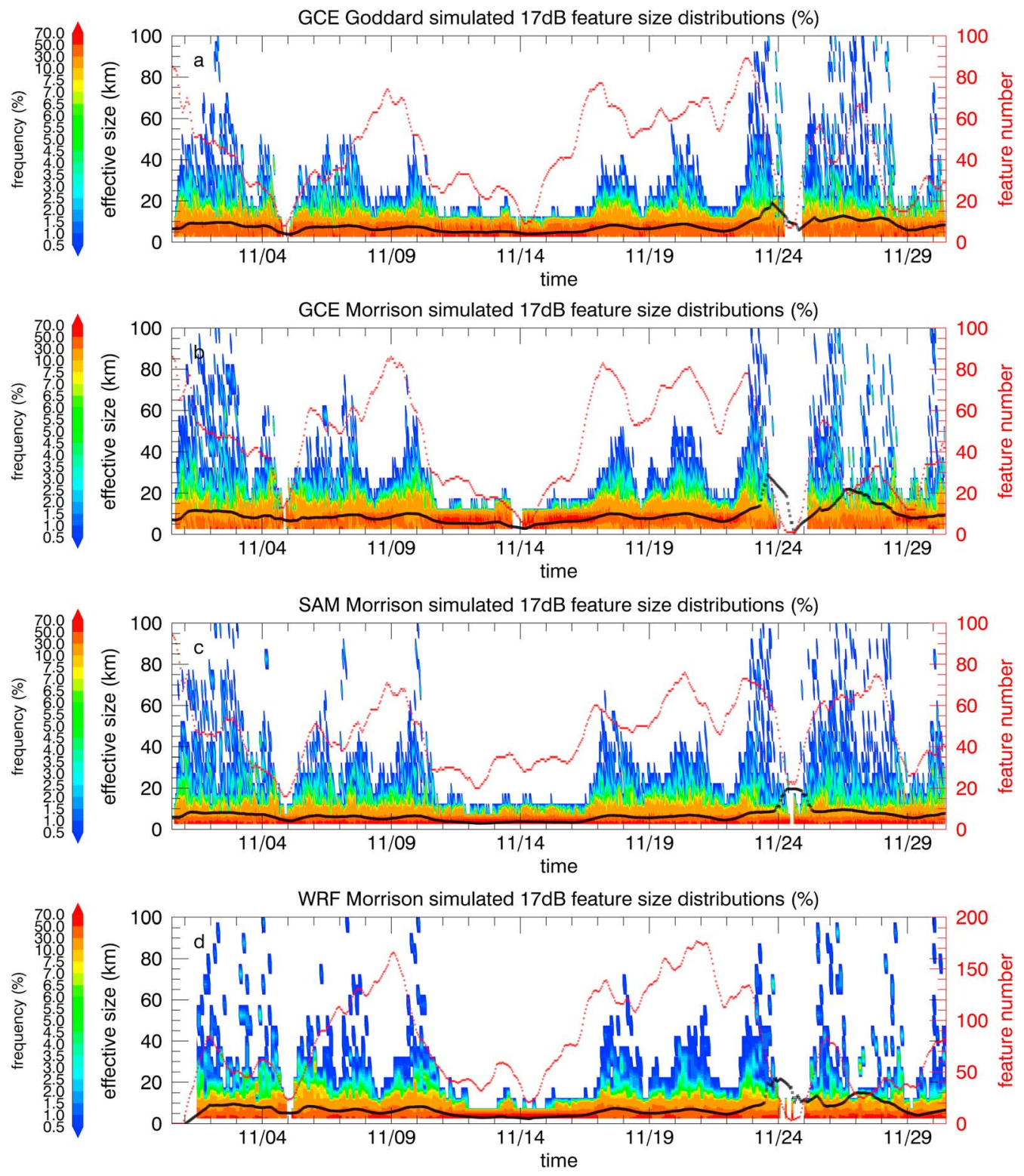

Figure 12. Same as Figure 6 except for different cloud-resolving model simulations. (a) The Goddard Cumulus Ensemble (GCE) model with the 3-ICE microphysical scheme; (b) the GCE model with the Morrison two-moment microphysical scheme; (c) the System for Atmospheric Modeling (SAM) model, also with Morrison scheme; (d) the Weather Research and Forecasting (WRF) model with Morrison scheme. 

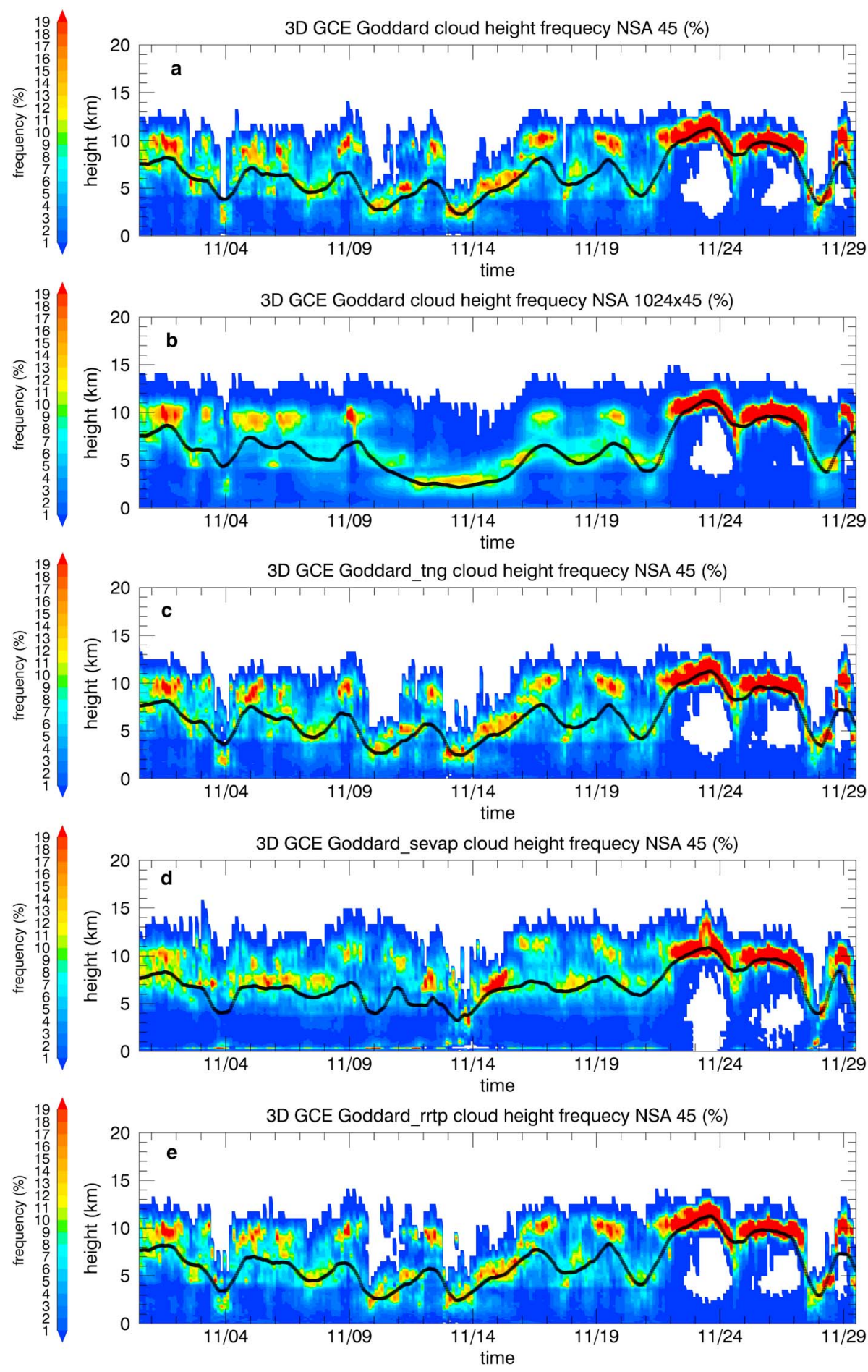

Figure 13. The same as Figure 11 except for Goddard Cumulus Ensemble (GCE) model with Goddard 3-ICE scheme, using coarser vertical resolutions of 45 vertical levels instead of 106 as shown in Figure 11. (a) The small-domain simulation using $256 \mathrm{~km} \times 256 \mathrm{~km}$ horizontal domain with $1 \mathrm{~km}$ resolution, as in all previous simulations. (b) Use of 1,024 km × 1,024 km horizontal domain with 1-km resolution. (c) The same as Figure 13a except for reducing graupel sizes in the Goddard microphysical scheme. (d) The same as Figure 13a except for removing cloud evaporation and ice sublimation where vertical air velocities are higher than $0.5 \mathrm{~m} / \mathrm{s}$. (e) The same as Figure 13a except for raising the upper boundary sponge layer $3 \mathrm{~km}$ higher. The dark lines again represent the median cloud top heights with a 24-hr running mean. NSA = northern sounding array. 

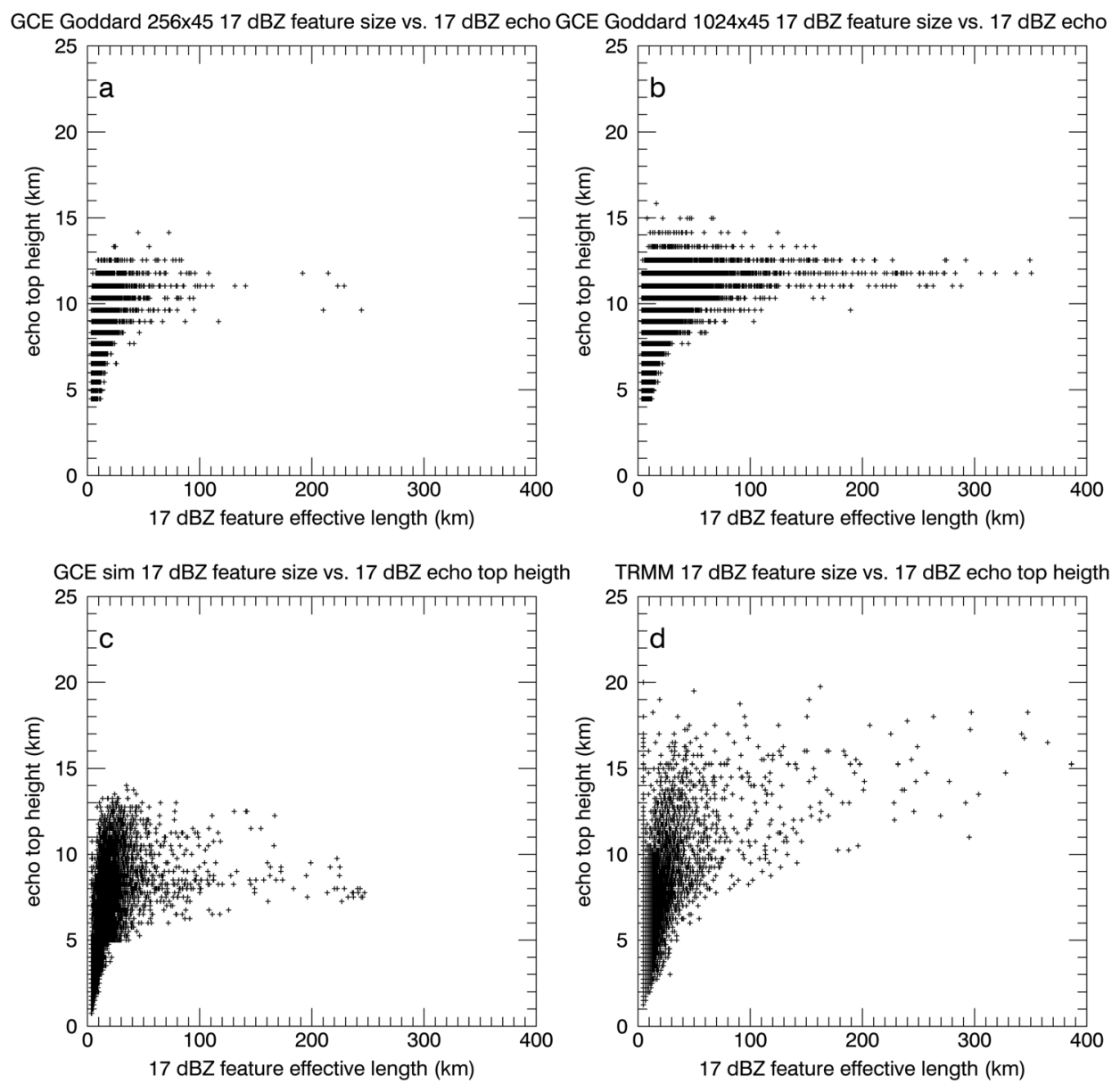

Figure 14. Scatter plots of the precipitation feature effective sizes versus the maximum 17-dBZ echo-top heights, showing feature sizes up to $400 \mathrm{~km}$ for largedomain simulation comparisons. (a and c) The small-domain simulations use $256 \times 256 \mathrm{~km}$ domain size. Figure 14 a has 45 vertical levels, and Figure $14 \mathrm{c}$ has 106 vertical levels. (b) The large-domain simulation with 1,024 × 1,024 km domain size and 45 vertical levels. (d) The Tropical Rainfall Measurement Mission (TRMM) observation. Figure 14d (Figure 14c) is the same as Figure 10a (Figure 10b) except for an extended $x$ axis range. GCE $=$ Goddard Cumulus Ensemble. 


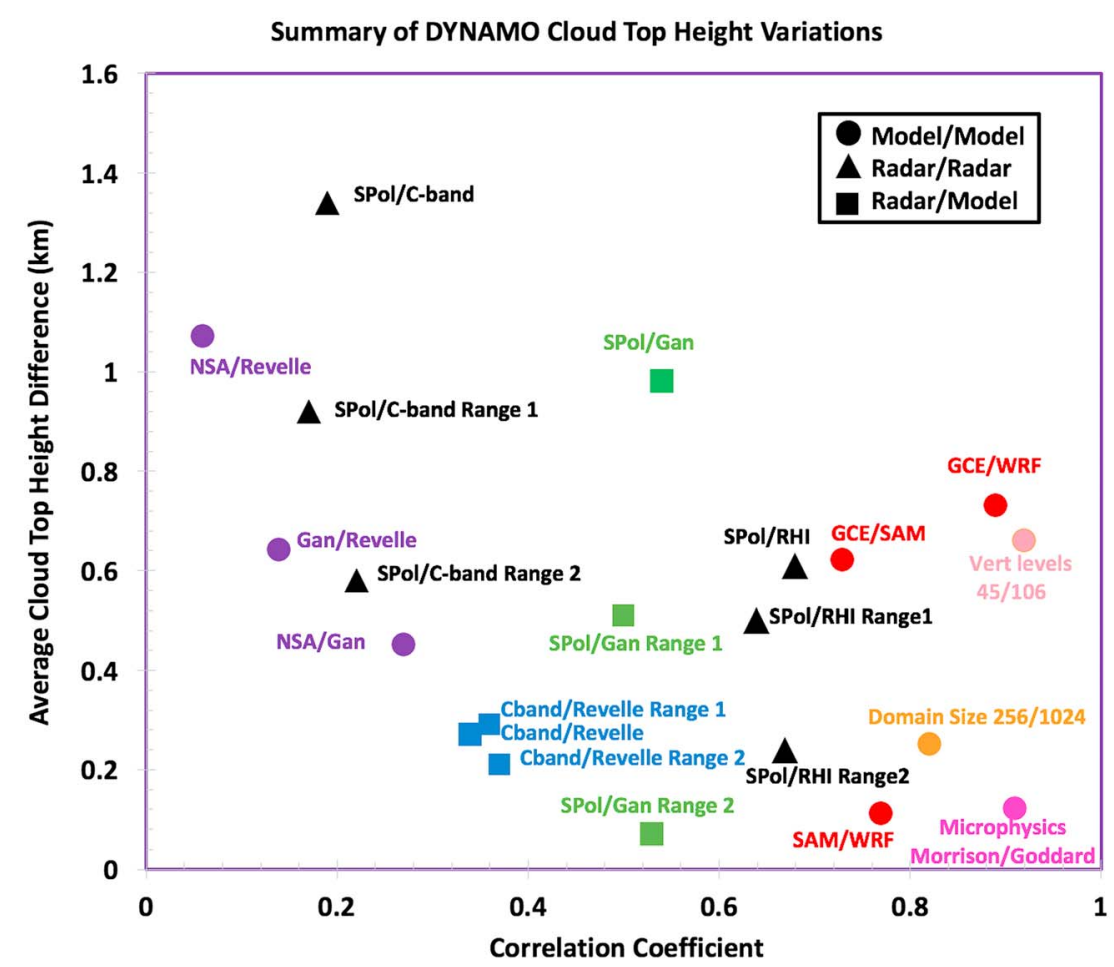

Figure 15. Summary of the radar echo-top height variations during the DYNAmics of the Madden-Julian Oscillation (DYNAMO) November Madden-Julian Oscillation event, using various observations and simulations. The $x$ axis is the correlation coefficients of the median echo-top height time series (the black lines in previous figures); the $y$ axis is their mean differences. Circles represent model-model comparisons; triangles are radar-radar comparisons; squares are model-radar comparisons. Each label indicates the single parameter that differs in the comparison pair, where the first label always has a higher echo-top height. In observations, range 1 represents subsampling of the original data range ( 0 to $150 \mathrm{~km}$ ), between 20 and $120 \mathrm{~km}$; range 2 is from 20 to $100 \mathrm{~km}$. GCE = Goddard Cumulus Ensemble; $\mathrm{NSA}=$ northern sounding array; WRF = Weather Research and Forecasting; SAM = System for Atmospheric Modeling. 